\title{
Integrated innovative biorefinery for the transformation of municipal solid waste into biobased products
}

Víctor Pérez ${ }^{1,2}$, Andrés Pascual ${ }^{3}$, Alfredo Rodrigo ${ }^{3}$, María García Torreiro ${ }^{3}$, Marcos Latorre-Sánchez ${ }^{4}$, Caterina Coll Lozano ${ }^{4}$, Antonio David-Moreno ${ }^{5}$, Jose Miguel Oliva-Dominguez ${ }^{5}$, Alba Serna-Maza ${ }^{6}$, Natalia Herrero García ${ }^{7}$, Inmaculada González Granados ${ }^{7}$, Rocio Roldan-Aguayo ${ }^{8}$, David OvejeroRoncero $^{8}$, Jose L. Molto Marin ${ }^{8}$, Mark Smith ${ }^{9}$, Hana Musinovic ${ }^{9}$, Amélie Raingué $^{6}$, Laurent Belard ${ }^{10}$, Celia Pascual ${ }^{1,2}$, Raquel Lebrero ${ }^{1,2}$, Raul Muñoz ${ }^{1,2}$

${ }^{1}$ Institute of Sustainable Processes, University of Valladolid, Valladolid, Spain; ${ }^{2}$ Department of Chemical and Environmental Engineering, University of Valladolid, Valladolid, Spain; ${ }^{3}$ AINIA-Centro tecnológico, Paterna, Valencia, Spain; ${ }^{4}$ Imecal S.A., L'alcudia, Valencia, Spain; ${ }^{5}$ CIEMAT, Madrid, Spain; ${ }^{6}$ Urbaser S.A., R\&D and Innovation Department, Madrid, Spain; ${ }^{7}$ Biomasa Peninsular S.A., Madrid, Spain; ${ }^{8}$ Exergy Ltd., Coventry, United Kingdom; ${ }^{9}$ NATRUE, Brussels, Belgium;

${ }^{10}$ NaturePlast, Ifs, France

\subsection{Introduction}

Globally, population tends to increase in urban rather than in rural areas. In 1950, 30\% of the world's population was urban, while in $2018,55 \%$ of the world's population is residing in urban areas and this figure is expected to grow until $68 \%$ by 2050 [1]. Thus, cities grow as major consumers of world's natural reserves and energy supplies, acting as concentrators of materials and nutrients, by aggregating inputs such as food from rural areas into a concentrated urban space. Considering that on average $483 \mathrm{~kg}$ of municipal solid waste (MSW) per capita are being produced in the EU, and the organic fraction of MSW (OFMSW) represents the largest fraction of the MSW (40\%-50\%), cities concentrate an enormous waste production as well, while the nutrients that return to the biosphere are nowadays considerably low [2]. Despite waste landfilling represents linear economy, still 24\% of the MSW is managed in this way. At the expense of landfilling, other treatment methods such as recycling, incineration and composting or anaerobic digestion (AD) are being utilized for MSW treatment, managing 29\%, 27\%, and $16 \%$ of 
the generated MSW, respectively [3]. Waste composting and AD yield a fertilizer product and the possibility of energy recovery obtaining biogas, however, both are considered lowvalue products.

In this regard, new biobased building blocks, chemicals and materials like bioplastics will be required in the near future to face concerns about the environmental impact, availability and high cost of oil and its derivative products. Plans for a new biobased economy are being developed by the EU and by almost all countries worldwide. Biorefineries are considered a key instrument for achieving the bioeconomy goals and for promoting the linear-to-circular transition in the EU economy. The fundamental contribution of biorefineries to the concept of circular economy is based on their ability to transform biomass into different final products with high added value. Municipal biowaste (waste from food consumed in homes, restaurants, markets and commercial premises, as well as biodegradable waste produced in gardens and parks) are mainly composed of carbohydrates, proteins and lipids, all of which represent high potential raw materials for the creation of valuable products.

An integral management of the MSW focused on maximum efficiency in the production of valuable resources could contribute to the economic transformation toward the circular economy model, according to the EU strategy about circular economy, and to the environmental and economic sustainability of the MSW management model [4].

In this context, the URBIOFIN biorefinery (developed under the grant agreement No 745785-Biobased Industries Joint Undertaking; European Union's Horizon 2020 research and innovation program) represents a proof of concept of the techno-economic and environmental viability of the conversion OFMSW into:

- Chemical building blocks (bioethanol, medium or short volatile fatty acids (VFAs), biogas).

- $\quad$ Biopolymers (low- and medium-chain polyhydroxyalkanoates (PHA), composites combining different PHA).

- $\quad$ Additives (bioethylene, nutrients for fertilizers).

By using the biorefinery concept applied to MSW (urban waste biorefinery), OFMSW is exploited as feedstock, taking into account its heterogeneity and variable composition, to produce at semiindustrial scale different valuable marketable products for local consumption. The processes involved in the development of these bioproducts are be interconnected, thereby a versatile and efficient biorefinery for OFMSW can be created. Urban biorefineries offer a new feasible and more sustainable scenario alternative to the current treatment of the OFMSW. The production, collection, and management of the MSW should be analyzed in the European context as a starting point to estimate how the MSW could be directed to local management systems based on biorefineries. 
In addition, waste biorefineries should aim at a versatile exploitation of OFMSW as feedstock according to their nature and composition. Thus, the most important industrial demands as well as the necessary synergies that allow the design of a versatile and efficient biorefinery must be identified.

The described biorefinery will validate the whole value chain at demonstration scale, including the implication of the waste management authorities and companies, technology developers and the validation of the final products by the end-users. The URBIOFIN biorefinery has been divided in three sections that include multiple improvements to the baseline treatment plant (Fig. 2.1). First, a fraction of OFMSW is pretreated, hydrolyzed and fermented into bioethanol, which will be catalytically converted into bioethylene to be used in fruit ripening applications. At the same time, the other fraction of OFMSW is treated in a two-phase AD unit, aimed at obtaining VFAs in the first stage and biogas in the second stage. Subsequently, the VFAs are biologically converted into short chain PHA or elongated with the bioethanol produced previously and further bioconverted into medium-chain PHAs to be used in packaging and agriculture. The VFA-free digestate can be mixed with the vinasse originated from

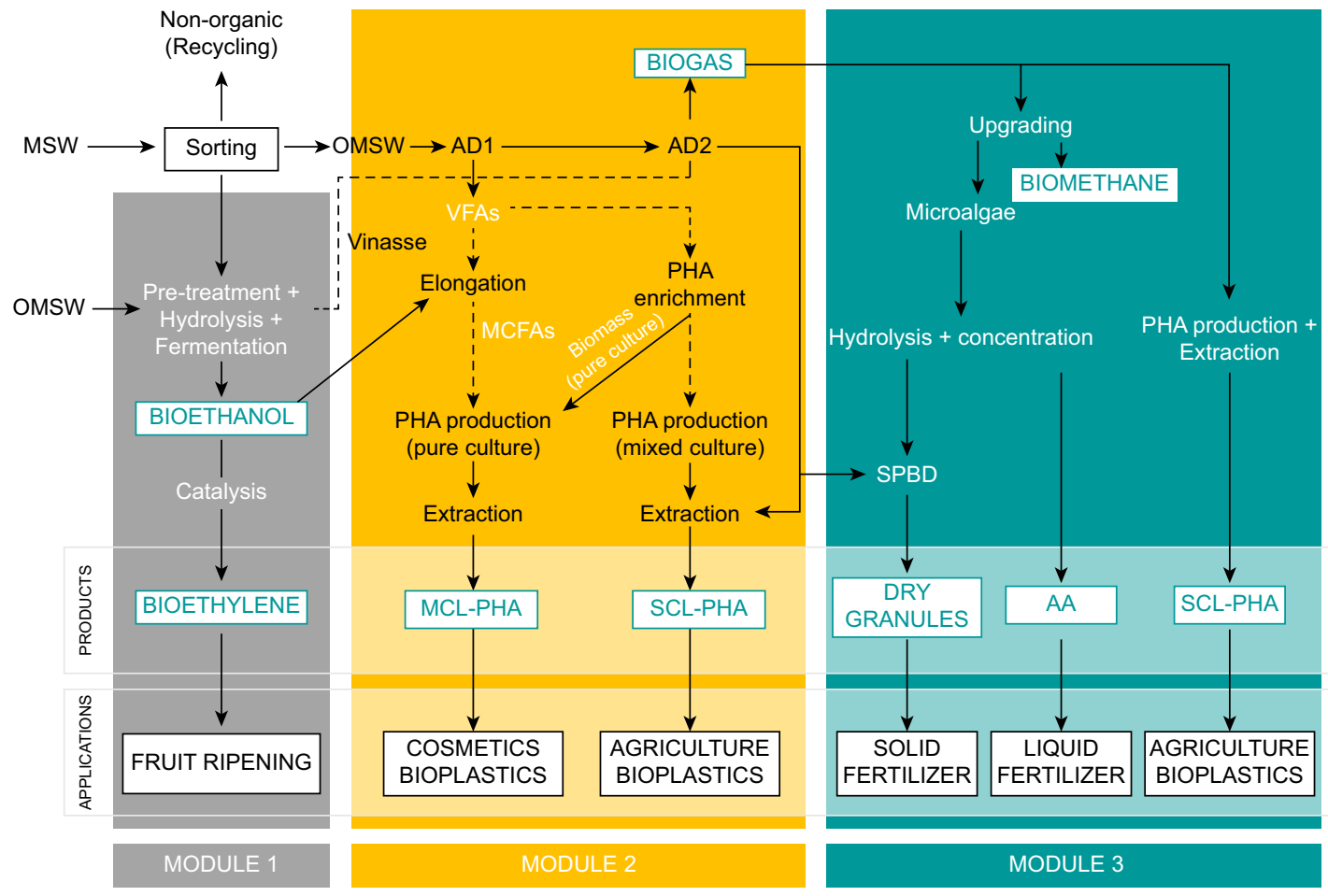

Figure 2.1

Overall URBIOFIN biorefinery diagram showing all biobased product lines. 
OFMSW fermentation and anaerobically transformed into biogas. Downstream, the biogas produced in the second stage of AD can be photosynthetically upgraded to biomethane to be injected into natural gas grids or desulfurized and bioconverted into PHAs for packaging applications. The microalgae produced during photosynthetic biogas upgrading, together with the digestate and residual biomass from AD, is employed in the formulation of biofertilizers.

The URBIOFIN biorefinery was achieved by implementing eight different work packages (WP), led by the different partners of the consortium according to Table 2.1. The managerial structure of the consortium is depicted in Fig. 2.2.

\subsection{Bioethanol from MSW as chemical building block}

Bioethanol industry has rapidly increased worldwide, being the most used biofuel today globally. In 2017, the total bioethanol production was estimated in about 84 billion metric tons [5]. These figures have also brought up the huge market potential of bioethanol as feedstock for the production of alternative biobased chemicals [6,7]. As illustrated in Fig. 2.3, bioethanol can be catalytically converted into a wide range of compounds, including ethylene, propylene, 1,3-butadiene, iso-butylene, hydrogen, acetaldehyde, ethylene oxide, $n$-butanol, acetic acid, ethyl acetate, acetone and dimethyl ether [9].

Table 2.1: Distribution of the work packages and work package leaders in the URBIOFIN project.

\begin{tabular}{|c|c|c|}
\hline WP No & WP title & WP leader \\
\hline 1 & $\begin{array}{c}\text { Preliminary actions for the urban biorefinery } \\
\text { design }\end{array}$ & AINIA \\
\hline 2 & $\begin{array}{l}\text { Conversion of OFMSW to bioethanol as } \\
\text { building block for the production of bioethylene }\end{array}$ & IMECAL \\
\hline 3 & $\begin{array}{c}\text { Conversion of OFMSW to VFAs for the } \\
\text { production of PHA }\end{array}$ & URBASER \\
\hline 4 & $\begin{array}{l}\text { Biogas bioconversion to biomethane and } \\
\text { added-value products }\end{array}$ & UVa \\
\hline 5 & $\begin{array}{l}\text { Final applications and industrial validation of } \\
\text { the biobased products developed }\end{array}$ & BPE \\
\hline 6 & $\begin{array}{l}\text { Integration of the urban biorefinery. Economic, } \\
\text { environmental and regulatory assessments }\end{array}$ & EXERGY \\
\hline 7 & $\begin{array}{l}\text { Communication, dissemination and exploitation } \\
\text { activities }\end{array}$ & $\mathrm{BCM}$ \\
\hline 8 & Project management & IMECAL \\
\hline
\end{tabular}




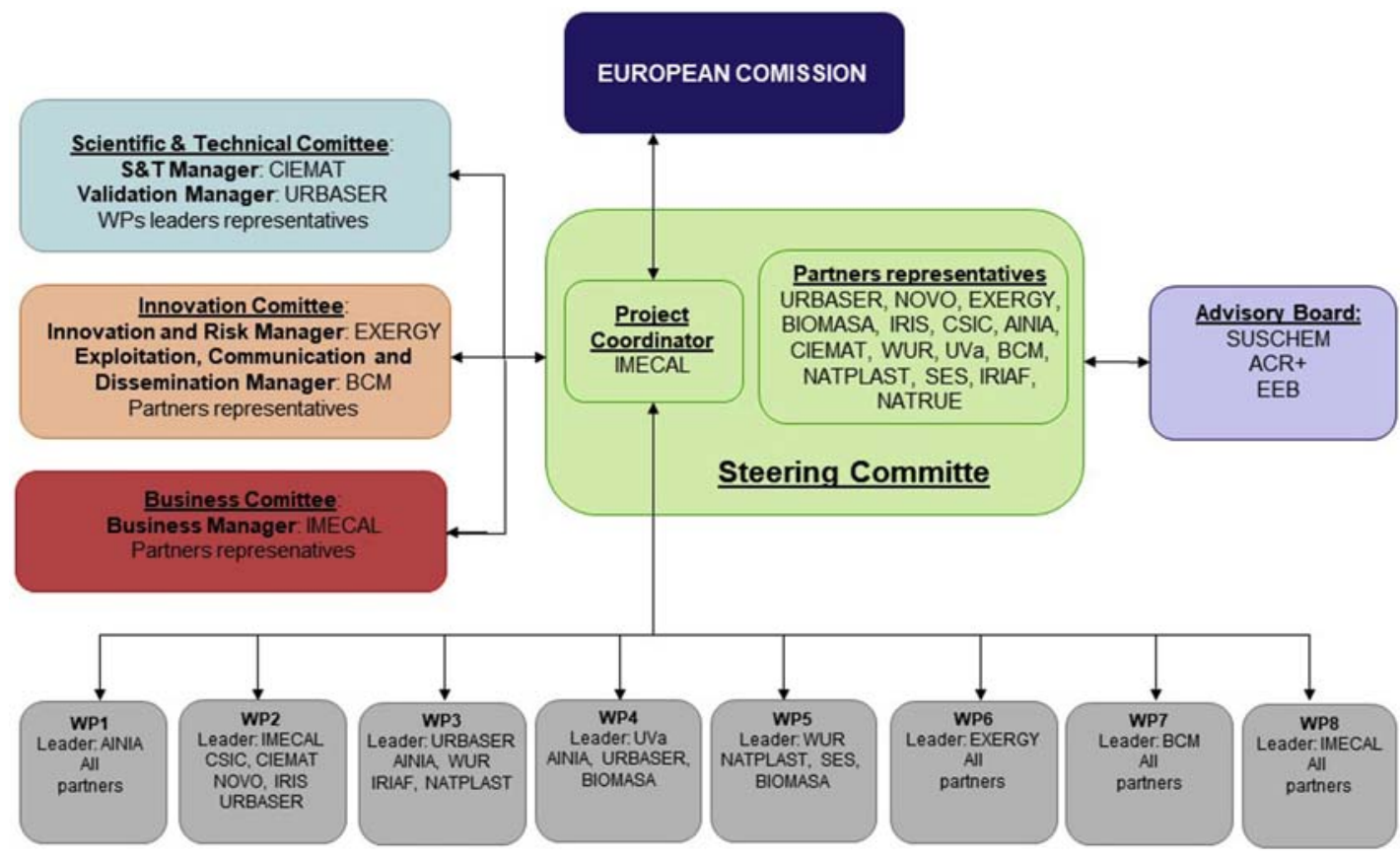

Figure 2.2

Scheme of the internal managerial structure of the URBIOFIN project.

Traditionally, bioethanol has been produced by converting edible sugar- and starchbased feedstock (e.g., sugarcane juice, molasses, corn) (Fig. 2.4). However, due to the competition with food and the concerns about ecological systems, recent research has shifted toward bioethanol production from nonfood biomass feedstock (lignocellulosic materials from agricultural, industrial and urban waste), which are low cost and abundantly available sources. In January 2013, bioethanol from lignocellulosic sources started to be produced at commercial scale [10]. Although its chemical composition greatly varies depending on factors such as culture, location, weather conditions, and degree of economy and development of a given society, the glucans contained in OFMSW have high potential as raw material for bioethanol production [11]. Starch and lignocellulosic carbohydrates (cellulose and hemicelluloses) from OFMSW can be converted into ethanol by either thermochemical or biochemical processing methods [12]. Bluefire, Coskata, New Planet Energy, Fulcrum and IMECAL (http://www. imecal.com/perseo/) are some examples of companies that have already developed technologies for converting OFMSW into ethanol at demonstration scale. Biotechnological OFMSW bioethanol production, such as the scheme proposed by IMECAL with its patented technology PERSEO Bioethanol, is preferred to thermochemical OFMSW bioethanol production due to the potential valorization of the 


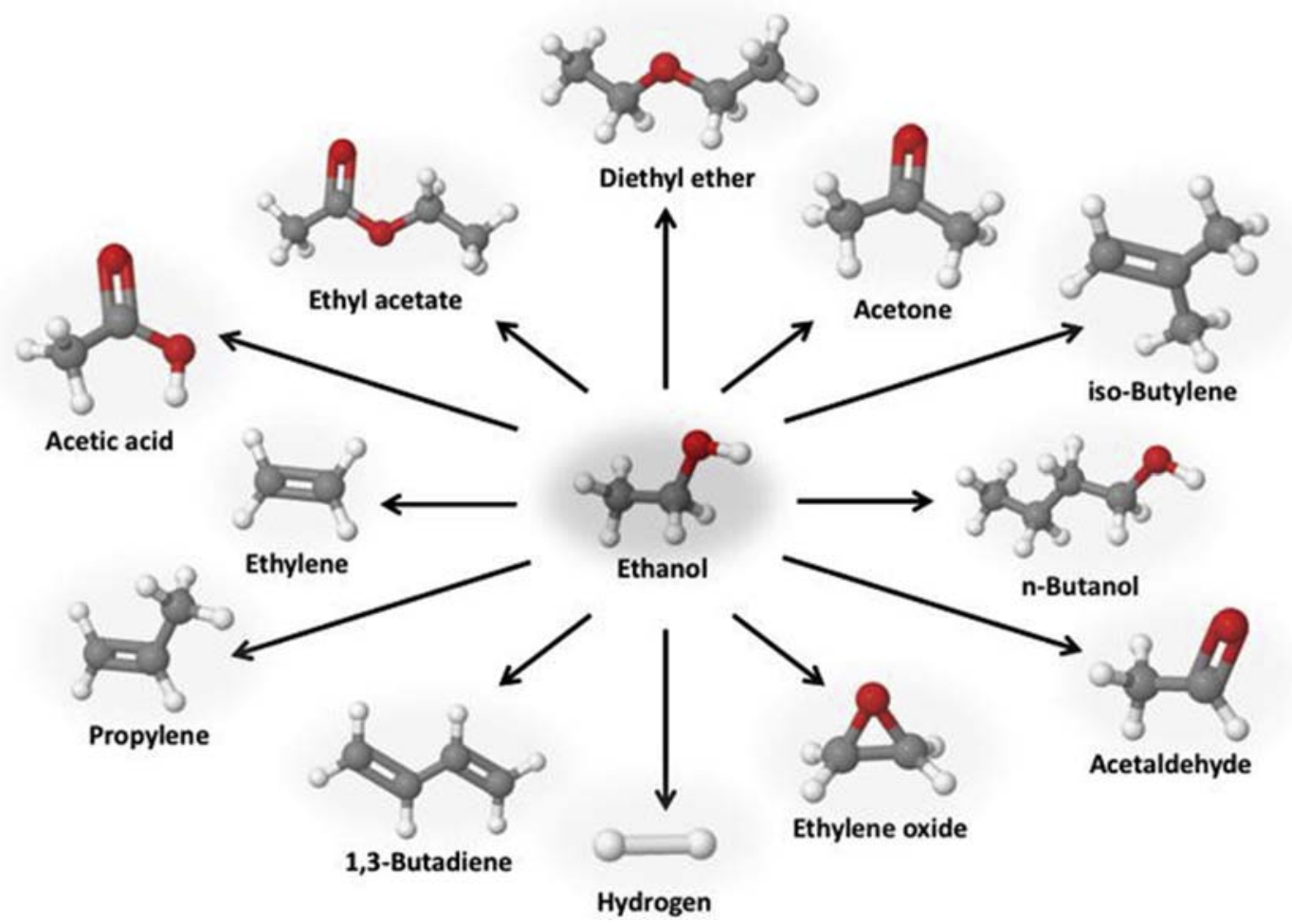

Figure 2.3

Ethanol as building block for the production of valuable chemicals. Carbon: dark gray; hydrogen: light gray; oxygen: red (black in print version). Molecule structures were obtained with JSME Molecular Editor [5,8].

remaining derived streams and its lower production costs. This process usually involves (1) a pretreatment step to ease the accessibility of hydrolytic enzymes to carbohydrates, (2) an enzymatic hydrolysis of starch, cellulose and hemicellulose, and (3) the subsequent microbial fermentation of the resulting sugars (mainly glucose) into ethanol. Compared to thermochemical processes, enzymatic processes avoid the presence of inhibitors to the fermentation stage. Saccharification and fermentation processes can either be performed separately, as separate hydrolysis and fermentation (SHF), or simultaneously, as simultaneous saccharification and fermentation (SSF). SSF strategies have shown superior process performance and better cost-effectiveness by reaching higher ethanol yields and reducing equipment needs by using a single reactor [13].

Current challenges for the biotechnological conversion of OFMSW into ethanol mainly include the development of improved process integration strategies, and increasing pretreatment and saccharification efficiencies. In URBIOFIN biorefinery, the pretreatment 


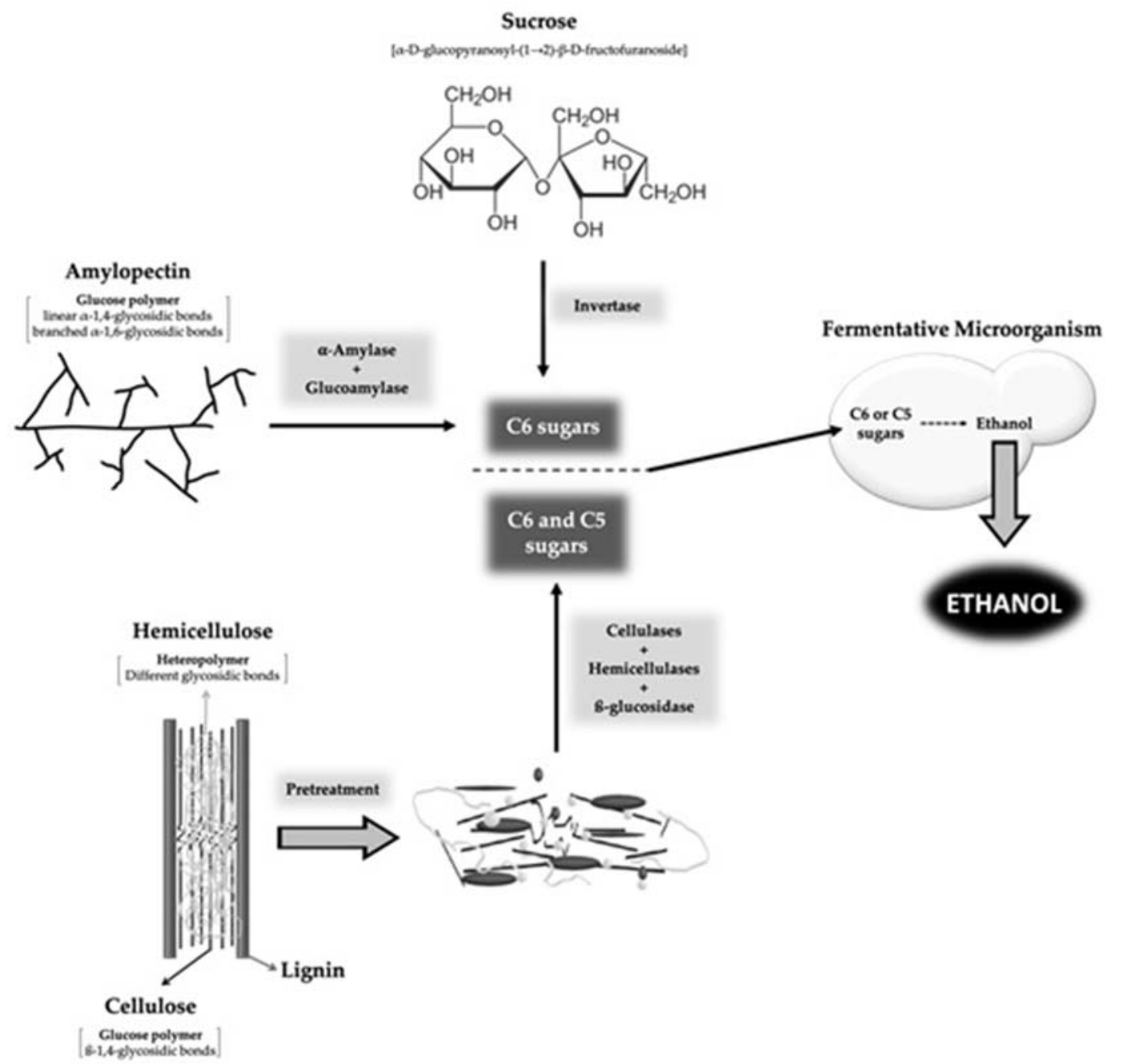

Figure 2.4

Simplified scheme for bioethanol production from sucrose (sugar-based materials), amylopectin (starch-based materials), and lignocellulose. While sucrose and amylopectin can be enzymatically hydrolyzed to directly yield fermentable sugars, lignocellulosic biomass requires a pretreatment

step in order to increase the accessibility of enzymes to carbohydrates. Subsequently, the resulting $\mathrm{C} 6$ and $\mathrm{C} 5$ sugars are then converted into ethanol by the corresponding fermentative microorganism.

conditions (e.g., temperature, catalyst type and concentration) and the use of novel tailormade enzyme cocktails to promote the effective depolymerization of cellulose and starch are being optimized to improve the OFMSW-based bioethanol economic competitiveness. Another critical aspect for the success of urban waste biorefineries is the development of 
the required process engineering for scaling-up technologies with such complex raw materials to a semiindustrial level. Finally, the technoeconomic improvements at the process engineering level determined in the previous stages of the project will be tested at the PERSEO Bioethanol semiindustrial plant (Fig. 2.5). The bioethanol produced in the URBIOFIN biorefinery presents the required quality as a chemical building block and can be further transformed into bioethylene.

\subsection{Ethylene from OFMSW derived bioethanol}

Ethylene is one of the most consumed chemicals worldwide, with a total production above 150 million tons in 2017 [14]. It is primarily a monomer used as a feedstock in the manufacture of plastic polymers (PE, PET, PEG, PVC and PS), fibers and other organic chemicals that are ultimately consumed in the packaging, transportation and construction industries, and in a multitude of industrial and consumer markets. Ethylene is also a gas plant hormone used for fruit ripening and degreening. During 2009-14, world ethylene consumption grew at an average rate of almost $4.5 \%$ per year and it is expected to grow at about $4 \%$ per year over the next 5 years [15].

Today, ethylene is mainly produced by cracking of naphtha in petrochemical industries [16]. However, concerns about climate change and global warming have encouraged the utilization of renewable materials and alternative energy sources instead of fossil resources. In conclusion, the catalytic dehydration of bioethanol has emerged as an alternative method to the fossil-based production of ethylene. The growing interest in this route to produce bioethylene is shown by the implementation of several commercial plants, which are currently in operation by companies such as Chematur, Braskem, TechnipFMC, or Axens, together with IFPEN and Total. The largest bioethylene production plant, with an annual production of 200,000 ton using sugarcane bioethanol as feedstock, is located in Brazil, [17]. In this context, bioethanol
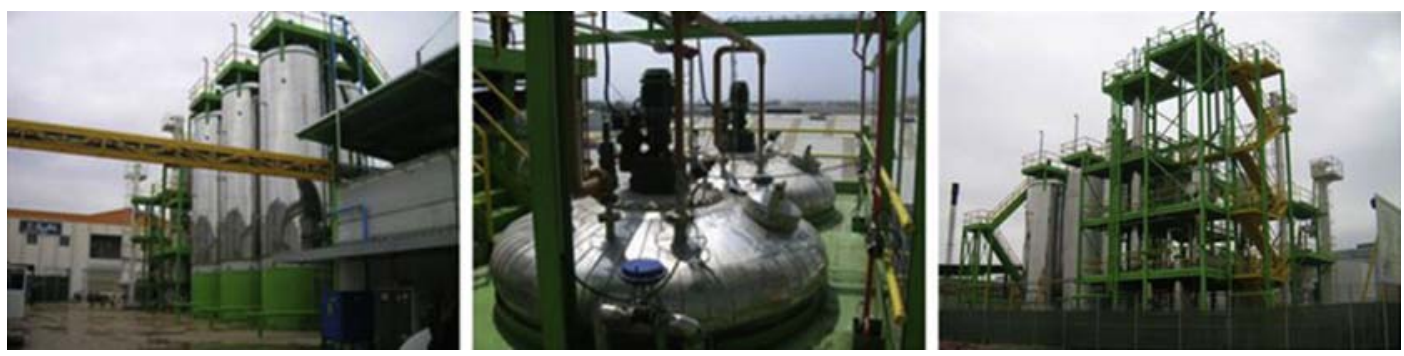

Figure 2.5

PERSEO Bioethanol demonstration plant of IMECAL (L'Alcúdia, Spain). 
can be catalytically dehydrated to produce bioethylene through chemical reaction (Eq. 2.1):

$$
\mathrm{C}_{2} \mathrm{H}_{5} \mathrm{OH} \leftrightarrow \mathrm{C}_{2} \mathrm{H}_{4}+\mathrm{H}_{2} \mathrm{O}
$$

The reaction of ethanol dehydration is endothermic, and ethylene yields are highly dependent on reaction temperature. The highest selectivity toward ethylene is obtained at $300-500^{\circ} \mathrm{C}$. Higher temperatures shift the reaction toward acetaldehyde production, while lower temperatures result in production of diethyl ether [18]. In addition, the reaction is reversible, with the equilibrium being hindered by higher pressures and the presence of water vapor in the feed. The dehydration reaction occurs in the vapor phase inside the reactor in the presence of the corresponding catalysts. Maximizing ethanol conversion yield is crucial, since recycling of unconverted ethanol is a highly energy intensive process. By using specific acid catalysts designed for this reaction, a wide number of process schemes can be considered for supplying the required heat for the endothermic reaction. Four types of acid catalysts are mainly used in the ethanol dehydration reaction: phosphoric acid, molecular sieves (ZSM-5 type, Si-Al-phosphate (SAPO) type), oxides (activated-alumina based catalysts) and heteropolyacid catalysts [19].

Depending on the product application, the raw ethylene produced in the reaction needs to be further purified to reach different chemical grades of ethylene. Today, most part of the ethylene produced in the petrochemical industry is devoted to plastic production. To perform a successful polymerization reaction, a very high purity polymer-grade ethylene is required since the presence of impurities in ethylene has negative effects on the polymerization [20]. Typical byproducts formed during the catalytic dehydration of bioethanol include ethane, propane, propylene, butylene, or acetaldehyde. The ethanol feedstock can also contain some impurities such as methanol, propanol, or butanol [21]. These components are typically removed by additional distillation towers. Other mineral impurities such as salts in the form of cations, calcium, magnesium, sodium, potassium, iron and sulfate anions, chlorides and acidity of acetic acid, and even other possible contaminants present, can be retained by using ion exchange resins, where cations and anions are retained in two independent columns packed with resins, thus adapting the ethanol to the purity requirements.

In the URBIOFIN biorefinery, bioethylene is produced by catalytic dehydration of second-generation bioethanol derived from OFMSW. The produced bioethylene is used for citrus fruits degreening and banana ripening applications in postharvest fruit chambers. In this case, purity is not so critical compared to polymer application, where purities over $99 \%$ are required. When used as ripening gas, ethylene is usually sold mixed with other gases such as $\mathrm{CO}_{2}$ or $\mathrm{N}_{2}$ (with a concentration lower than $10 \%$ ) to form a nonflammable mixture developed specifically to allow effective ripening without 
the high flammability risks of pure ethylene. The ethylene concentration necessary for ripening ranges from 5 to $150 \mathrm{ppm}$ with exposure times between 12 and $72 \mathrm{~h}$ [22].

Considering bioethylene production as an independent process, the cost of this technology mainly depends on the feedstock price (i.e., bioethanol price). Thus, it is estimated that, depending on the region, bioethanol cost accounts for about $60 \%-75 \%$ of the bioethylene production cost [17]. Based on the fact that bioethanol production is a part of URBIOFIN biorefinery, the main cost of bioethylene production is associated to the energy consumption required to reach the high temperatures that shift the equilibrium toward ethylene production.

Another important aspect to consider during bioethylene production is catalyst deactivation. Although the catalyst is not consumed during the reaction, it can be deactivated, thus losing its ability to catalyze the reaction. The deactivation of the catalyst depends on: (1) the impurities contained in ethanol feedstock, (2) the conditions at which the reaction takes place, and (3) the catalyst nature. For instance, deposition of the coke formed during bioethylene production (depending on process conditions) is one of the main factors affecting catalyst deactivation. To prevent the conversion of ethylene into coke, the residence time for the ethylene product has to be kept as low as possible. Notwithstanding, such deactivation process is not fast, and the replacement of catalyst does not imply a critical cost in the process. During the plant operation, the possible impact of the associated impurities on the catalyst as well as on the chemical activity, selectivity and lifespan must be analyzed. The use of a modified catalyst could entail a reduction in the reaction temperature and therefore the energy consumption. However, changes in the catalyst have to be carefully evaluated because they can severely impact on the conversion yield, selectivity to the desired product and reaction stability. The chemical conversion, yield, and selectivity of the ethanol-to-ethylene catalytic reaction will be monitored by the installation of an in-line gas chromatograph in the pilot module. In the case that the catalyst lifespan under demo conditions is low, the cause of deactivation process will be studied and the required modifications of the catalyst to reduce the deactivation would be evaluated.

In conclusion, the catalytic dehydration of bioethanol to bioethylene is an alternative route to fossil-based production of ethylene that decreases the environmental impact of this chemical. Production of bioethylene from first generation bioethanol is a commercial process and several industrial plants are currently in operation. However, there is still no commercial process producing bioethylene from second generation bioethanol. An innovative bioethanolto-bioethylene process for the production of bioethylene by catalytic dehydration of secondgeneration bioethanol derived from OFMSW is implemented in the core of the URBIOFIN biorefinery. This process constitutes a key market advantage for the potential customers of this biobased product. Particularly, the bioethanol-to-bioethylene demonstration module is 
located downstream in PERSEO Bioethanol pilot plant of IMECAL project coordinator (http://www.imecal.com/perseo/) located in L'Alcudia (Valencia, Spain).

\subsection{VFA production from OFMSW}

Traditionally, biodegradable waste has been transformed into biogas via AD to avoid the loss of its potential energy and to reduce the amount of waste going to landfill. In the process, anaerobic consortia conduct a series of syntrophic chemical reactions named hydrolysis, acidogenesis, acetogenesis and methanogenesis. Disposal of OFMSW currently faces environmental and economic challenges. Process efficiency, operational and equipment costs of biobased technologies need to be optimized to compete with fossil fuel-based commodities, e.g., natural gas and shale gas. Favoring the production of methane in the series of anaerobic reactions, the opportunity of obtaining a more profitable product is lost, since VFAs produced during the acetogenesis stage attain higher cost in the market [23].

Nowadays, the use of VFA produced by means of mixed culture fermentation through various fermentation pathways suffers from a severe handicap. The VFAs mixture produced has no clear economic value considering that the individual separation of VFA is not technically and economically feasible. An alternative in to surpass this economic issue in waste biorefineries is using the effluent from acidogenic AD directly in downstream processes, avoiding expensive purification processes, as nutrient and carbon source for biological processes for the production of both medium-chain fatty acids (MCFA) and PHA.

$\mathrm{AD}$ is still the core process technology of modern biorefineries, with the potential of waste stabilization, recovery of chemical building blocks for the carboxylate platform, renewable energy, and nutrients (Fig. 2.1). A two-phase AD system, comprised of a hydrolytic digester and a methanogenic digester, is operated to convert OFMSW in chemical building blocks (VFAs and biogas). Additionally, digestate is also used to generate solid and liquid biofertilizers, in order to valorize the whole OFMSW content. Mesophilic dry anaerobic digesters with VALORGA configuration are recommended due to their flexibility and ability to treat feedstock with high quantity of inert materials as it can be expected in mechanically sorted OFMSW (Fig. 2.6). It represents also an advantageous configuration due to the need for a low feedstock dilution, maximizing product and nutrients concentrations for its recovery in downstream processes.

The population of methanogens must be inhibited in the first hydrolytic digester of the 2phase AD system in order to promote biological VFA production. This can be done by applying inoculation strategies of thermal pretreatment, $\mathrm{pH}$ shocks or inhibitor supplementation [24-27]. A most suitable approach to reduce operational costs and obtain an effective start-up of the hydrolytic digester is to inhibit the production of methane by overfeeding the methanogenic population. High organic loading rates (OLR) 


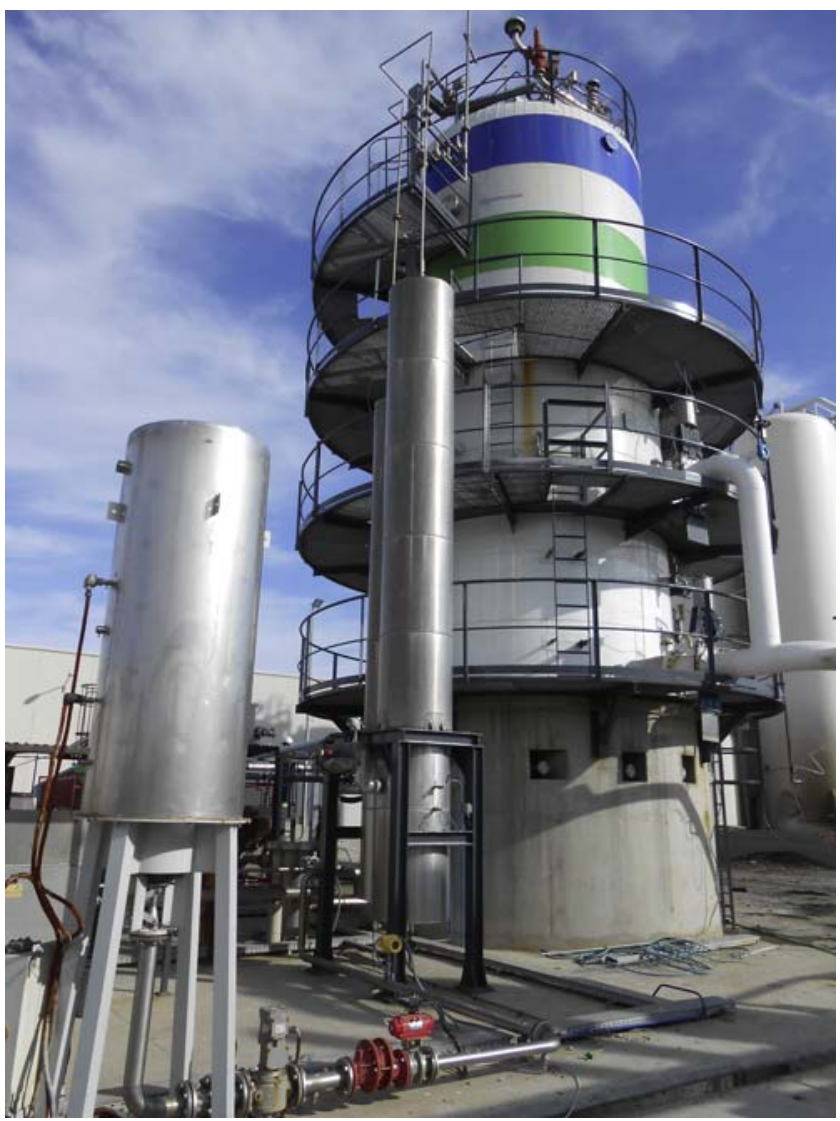

Figure 2.6

Hydrolytic digester installed in URBASER's research center (CIAM, Zaragoza).

cause imbalance between the acidogenic and methanogenic populations, accumulation of VFA in the digester, a decline in buffer capacity, a $\mathrm{pH}$ decrease and the complete inhibition of the methanogenic stage [28]. The use of a high protein content feedstock can also generate an inhibitory ammonia concentration in the digester at high OLR, producing VFA concentrations as high as $100 \mathrm{~g} / \mathrm{L}$ [29]. In the case of OFMSW, only thermophilic temperature can reach inhibitory ammonia concentrations [30].

Fig. 2.7 shows the general degradation route of particulate organic matter to VFA in the AD process. Anaerobic microorganisms compete for substrate in the complex metabolic pathways found in mixed culture fermentative systems. The activity of the enzymes involved in the hydrolytic step is vulnerable to decrease when the operational $\mathrm{pH}$ is not in the optimal range (5-7) [32]. This is the first essential and rate limiting stage in the anaerobic degradation of complex substrates such as OFMSW to VFA. Additionally, it is 


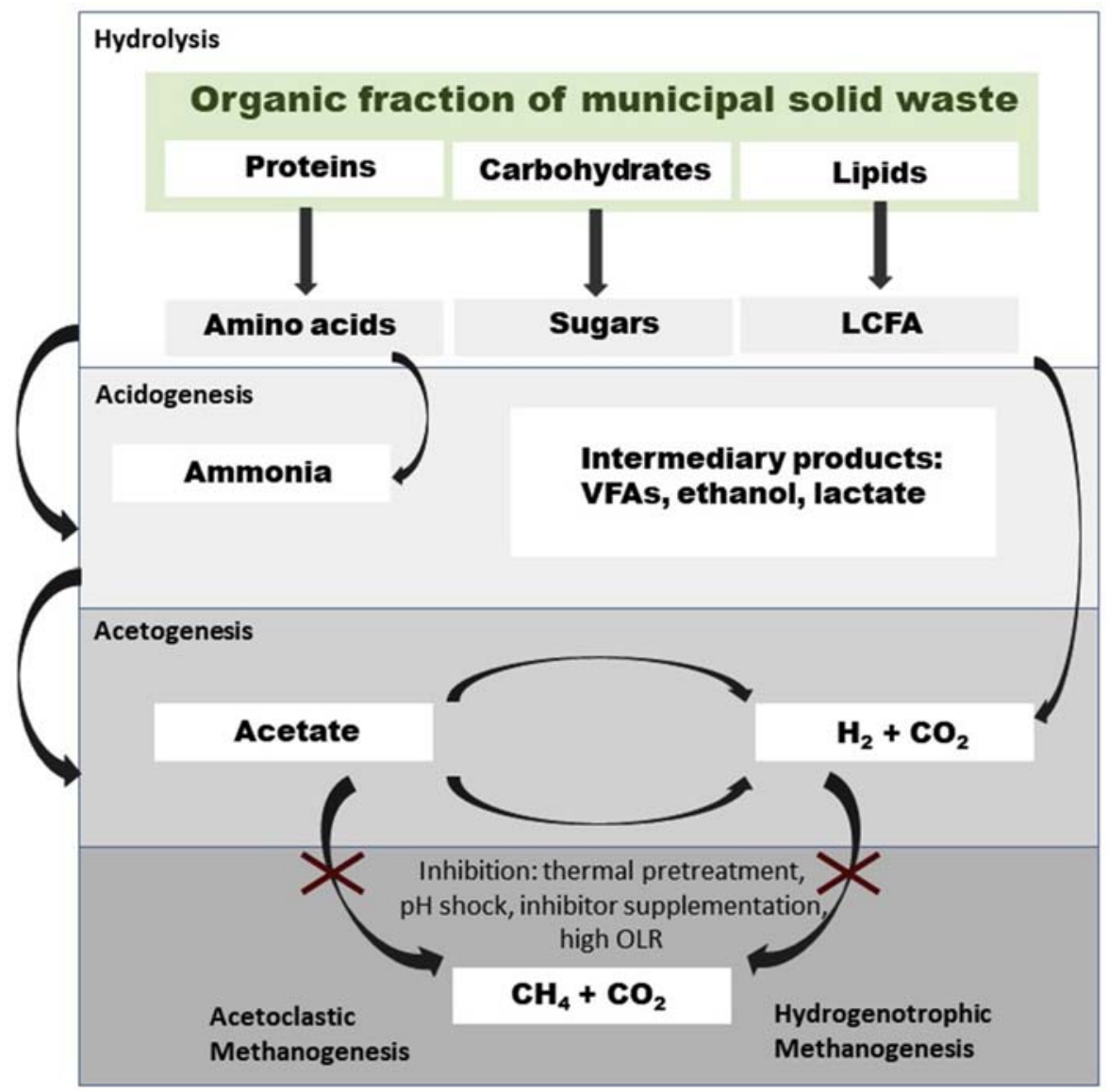

Figure 2.7

Anaerobic conversion of organic fraction of municipal solid waste to volatile fatty acids [31]. Modified Arslan D., Steinbusch KJJ, Diels L, Hamelers HVM, Strik DPBTB, Buisman CJN, De Wever H. Selective short chain carboxylates production: a review on control mechanisms to direct mixed culture fermentation. Critical Reviews in Environmental Science and Technology 2016;46(6):592-634.

key to maintain the operational $\mathrm{pH}$ value out of the optimum range for methanogenic archaea (6.8-8) in order to minimize $\mathrm{CH}_{4}$ production. Therefore, the most advantageous $\mathrm{pH}$ interval to maximize acidification is $5-6$, with or without $\mathrm{pH}$ control.

Several parameters such as the hydraulic retention time (HRT), OLR, $\mathrm{pH}$, temperature and trace element concentration, can be controlled in order to alter the VFA yield and spectrum of individual VFAs produced. Additionally, the use of feedstock pretreatments, e.g., hydrothermal or alkaline, can stimulate the production of VFA at a restrictive cost $[33,34]$. Special attention needs to be paid when selecting the equipment for solid-liquid separation of the partially digested effluent. Dewatering represents a fundamental process 
in the treatment and valorization of waste. In particular, when the suspended biomass is still present in the liquid fraction of the digestate, it may compete with the specialized aerobic biomass that utilize the soluble molecules, i.e., VFA and nutrients, to produce PHA. Additionally, the solid stream of hydrolysate will be further treated in a conventional anaerobic digester for the production of biogas, which will be further bioconverted into PHA and biomethane.

\subsection{PHA production from VFA}

PHAs are a family of biodegradable polyesters with thermoplastic properties, produced by a wide variety of microorganisms as intracellular energy and carbon reserve material [35]. Industrial interest on PHA rely on its similar properties to common thermoplastics polymers derived from petrol such as polypropylene. However, in contrast with synthetic polymers, PHAs present the advantage of being based on renewable resources and completely biodegradable by a wide variety of microorganisms and under different environmental conditions $[36,37]$.

Generally, PHA are classified into two main groups according to the number of carbon atoms that comprise their monomeric unit. Thus, short chain length PHA (scl-PHA) consists of three to five carbon atoms, whereas medium-chain length PHA (mcl-PHA) consists of 6-14 carbon atoms. PHA monomeric structure is directly related with the final physical properties of the material, determining its further applications. The monomer composition obtained depends on both the type microorganisms and nature of the carbon sources used. Polyhydroxybutyrate (PHB) is the most common scl-PHA and is characterized as a stiff and brittle material. From the incorporation of 3-hydroxyvalerate (HV) monomers into PHB, the resultant co-polymer becomes into a more flexible and easily processed by heat material proportionally to the amount of $\mathrm{HV}$ introduced. According to their intrinsic properties, scl-PHA are generally used for packaging material and disposable items, whereas mcl-PHA, which are characterized as elastomers, are suitable for film production and for high-value added applications such as surgical sutures, implants, drug delivery, etc. [38].

An environmental analysis of plastic production processes was carried out by comparing the petroleum-based polypropylene (PP) and the biological-based PHB production processes using LCA [39]. PHB was superior to PP in all the LCA categories. The energy requirements for $\mathrm{PHB}$ production are significantly lower than those of petroleum-based plastics. However, the environmental benefits that could be obtained by the replacement of conventional plastics by biopolymers may entail an important economic loss [40]. The main factors that increase the final costs of PHA are the price of the substrates used as a carbon source, bacterial productivity and downstream processing [41]. 
Several microorganisms with the ability to accumulate PHA at high yields have been studied in recent years, Ralstonia eutropha being one of the most referenced and wellknown microorganisms due to its high productivities (up to $5 \mathrm{~g} / \mathrm{L} \mathrm{h}$ ) [42]. Despite pure bacterial cultures are constantly investigated due to their high productivity, more efforts are necessary to develop bioprocesses for the valorization of waste streams and byproducts maintaining those high productivities. Since each type of waste or byproduct has different composition and characteristics, the selection of the appropriate microorganisms is of great importance.

An alternative scenario to pure cultures or engineered strains that would contribute to a reduction in production costs relies on the use of microbial mixed cultures (MMC). This approach is based on the utilization of mixed microbial consortia, operated under nonsterile conditions and ecological selection principles, where the operational conditions imposed on the biological system promote the development and maintenance of PHAaccumulating microorganisms. The efficiency of MMC for PHA production depends, to a great extent, on the microbial selection of the cultures by the application of different operational conditions on the bioreactor, known as enrichment step. Thus, PHA production with MMC is typically carried out in two different phases or stages, i.e., culture selection or enrichment and PHA accumulation. The separation of these two phases on two different bioreactors allows a better process optimization, since the optimal conditions and operational regimes of each stage are different. The main challenge of the enrichment step is the production of a culture highly enriched on PHA producing microorganisms and at high biomass concentrations. There are many methodologies to carry out the enrichment step, but one of the most employed is the classical aerobic dynamic feeding [43]. Enrichment process initiates with an aerobic sludge from a wastewater treatment plant, which is subjected to feast-famine cycles, where culture is first under an excess of carbon source and then under a limitation period of carbon source much longer than the feast phase. Microorganisms able to transform carbon source during feast period into PHA will have higher surviving rates during famine phase, since the stored PHA can be used as carbon and energy source, which allows them to outcompete the non-PHA-accumulating microorganisms. The enrichment step is the key reaction in the global scl-PHA production process. The purpose of the enrichment step is promoting the selection of those microorganisms able to accumulate PHA, and it determines the PHA-storing capacity of the MMC, but the operational conditions of this step also determine the biomass content on the system. Since PHA is an intracellular product, the biomass content reached in the enrichment phase is a rate limiting step of the process, similarly to the PHA-storing capacity of the system. In particular, the operational conditions applied during enrichment step, such as hydraulic retention time, solid retention time, organic loading rate and cycle length, together with the VFA stream composition, are directly related with the characteristics of the enriched biomass obtained after this process. 
The biomass obtained in the enrichment step under stationary conditions is transferred to the accumulation step, where a continuous feeding of VFA stream is applied under nutrient ( $\mathrm{N}$ and/or $\mathrm{P}$ ) limitation conditions in order to obtain a biomass with a high PHA content. PHA production by MMC was successfully achieved for different type of industrial waste streams, which rendered this approach a promising option for cost reduction in PHA production $[38,44,45]$.

In the URBIOFIN biorefinery, the valorization of waste byproducts as a feedstock to produce two different types of PHA using both pure and microbial mixed cultures has been implemented. On the one hand, the VFA present in the stream derived from the anaerobic hydrolyzation of OFMSW are biologically elongated to MCFA. Then, these MCFA are used as substrate to produce mcl-PHA using pure cultures (Fig. 2.8) of Pseudomonas strains, well-known mcl-PHA producers able to assimilate a wide range of carbon sources including fatty acids [46].

On the other hand, the VFA present in the stream derived from the anaerobic hydrolysis of OFMSW are used as direct substrate for scl-PHA using MMC following an aerobic

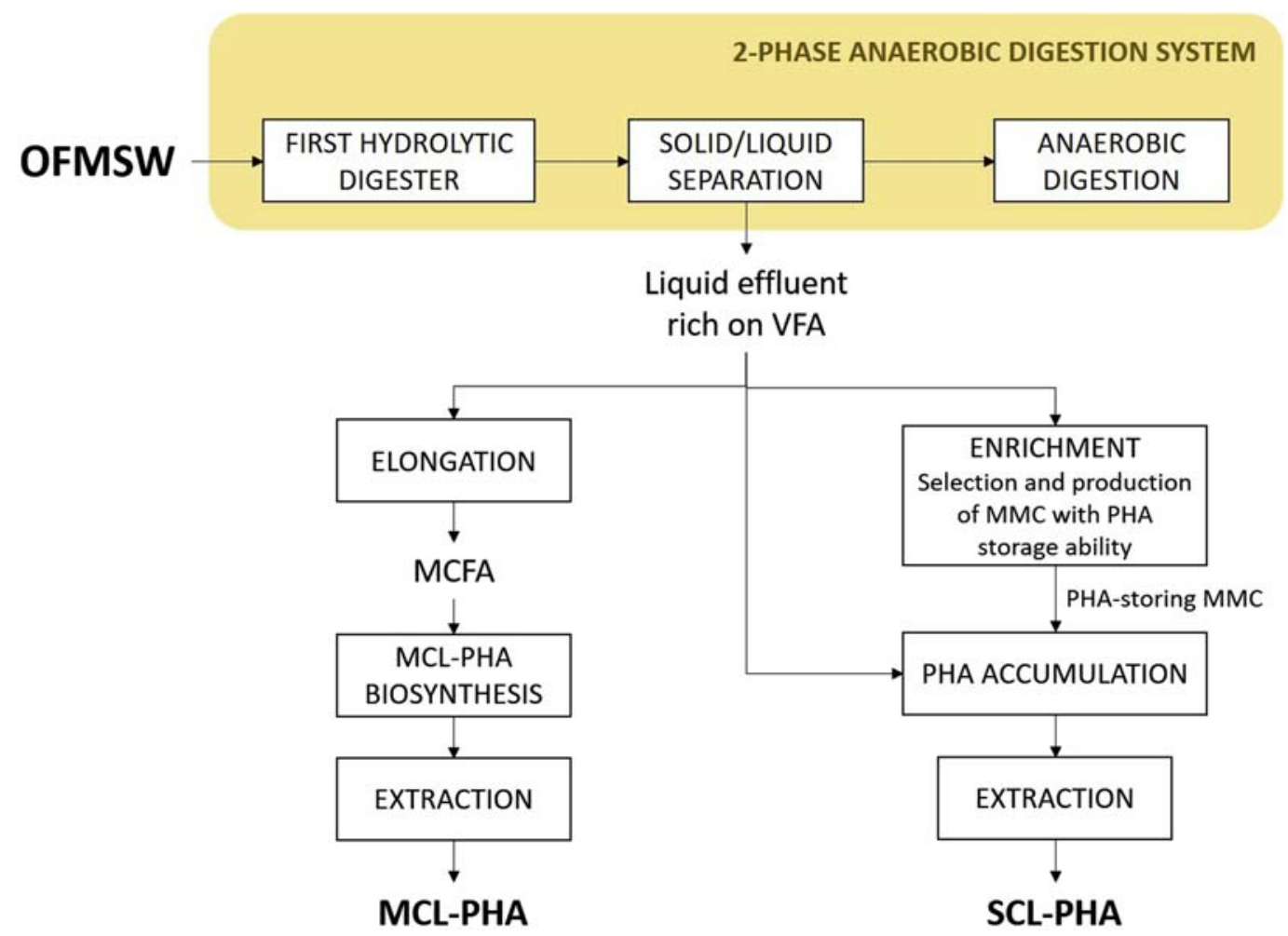

Figure 2.8

Block diagram for both scl- and mcl-PHA production in URBIOFIN. 
dynamic feeding regime during enrichment step (Fig. 2.8). Finally, both types of biomass are subjected to an extraction procedure, adapted for each biomass requirements in order to obtain the final PHA products.

\subsection{Biomethane production}

The presence of pollutants such as $\mathrm{CO}_{2}, \mathrm{H}_{2} \mathrm{~S}$ and volatile methyl siloxanes (VMSs) in biogas limits its use as a renewable alternative to fossil natural gas. The purification of raw biogas into biomethane, typically referred to as biogas upgrading, allows the injection of this green gas biofuel into natural gas grids or its use in automation [47]. Today, $\mathrm{H}_{2} \mathrm{~S}$ removal at commercial scale is carried out using adsorption-based technologies or in-situ chemical precipitation in the digester, while VMSs removal is conducted in activated carbon/silica gel filters or by cryogenic condensation [48,49]. On the other hand, water scrubbing and membrane separation rank among the most popular technologies for $\mathrm{CO}_{2}$ removal, along with pressure swing adsorption and chemical scrubbing [47]. In this context, while research on biofiltration in the past decades has resulted in biological reactors such as biotrickling filters (BTF) for $\mathrm{H}_{2} \mathrm{~S}$ removal at commercial scale, biotechnologies for $\mathrm{CO}_{2}$ abatement such as hydrogenotrophic or photosynthetic biogas upgrading are currently at a validation stage in demo-scale prototypes, and biological siloxane removal is still in a proof-of-concept stage. The simultaneous removal of $\mathrm{H}_{2} \mathrm{~S}$ and $\mathrm{CO}_{2}$ from biogas in an algal-bacterial photobioreactor and siloxane removal in a twophase partitioning bioreactor (TPPB) has been for the first time implemented at demoscale in the URBIOFIN biorefinery.

The presence of $\mathrm{CO}_{2}$ in biomethane decreases its specific calorific value, while $\mathrm{H}_{2} \mathrm{~S}$ is highly corrosive, toxic, and malodorous. Photosynthetic biogas upgrading is an emerging biotechnology engineered at Valladolid University (Spain) capable of removing simultaneously $\mathrm{H}_{2} \mathrm{~S}$ and $\mathrm{CO}_{2}$ based on the symbiotic interactions between alkaliphilic microalgae and bacteria [50]. Microalgal-bacterial consortia are cultivated in a photobioreactor (typically an open high rate algal pond (HRAP), where dissolved $\mathrm{CO}_{2}$ is photosynthetically fixed in the form of algal biomass in the presence of light) interconnected to a bubble absorption column (where $\mathrm{CO}_{2}$ and $\mathrm{H}_{2} \mathrm{~S}$ are absorbed) via recirculation of the algal cultivation broth (Fig. 2.9). In the absorption column, $\mathrm{H}_{2} \mathrm{~S}$ is oxidized to sulfate by litoautothrophic bacteria using the $\mathrm{CO}_{2}$ (as a carbon source) and the $\mathrm{O}_{2}$ (as electron donor) present in the cultivation broth. $\mathrm{O}_{2}$ stripping from the cultivation broth to the biomethane is considered as the rate limiting step of this upgrading technology. A recent optimization of this technology has shown that the implementation of a settler between the HRAP and the absorption column allows the operation of the column with a biomass-free scrubbing solution and the possibility to control biomass productivity by setting a fixed biomass wastage rate [51]. The nutrients (nitrogen and phosphorus) and 


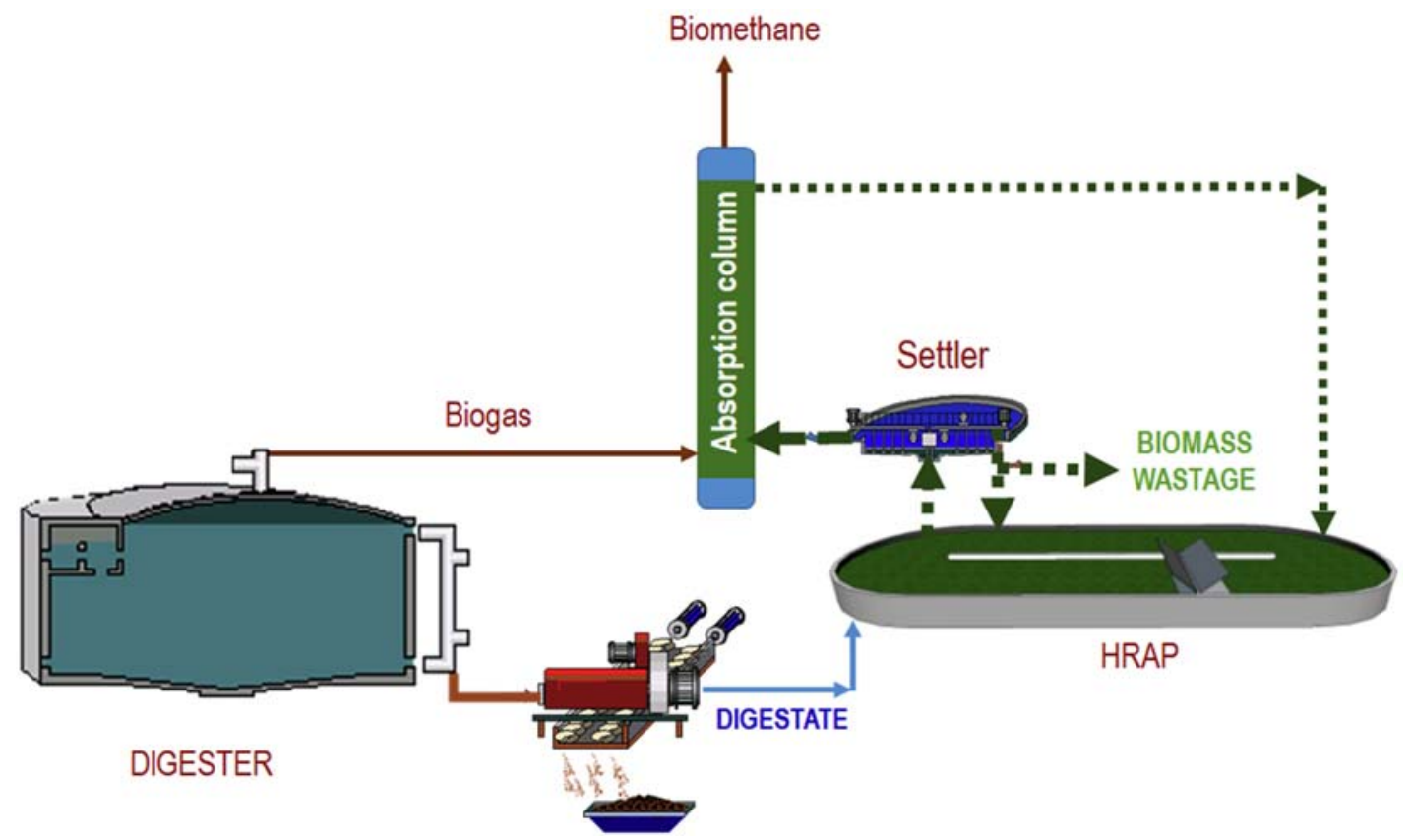

Figure 2.9

Schematic diagram of a photosynthetic biogas upgrading process coupled to nutrient recovery in the form of algal biomass.

water required to support microalgae and bacteria growth can be obtained from the digestate produced in the anaerobic digester, which entails an opportunity to produce microalgae-based biofertilizers while reducing the eutrophication potential of these highstrength wastewaters. This technology has been recently optimized in a $180 \mathrm{~L} \mathrm{HRAP}$ indoors and outdoors in the context of domestic wastewater treatment, with a consistent production of a biomethane complying with most international regulations $\left(\mathrm{CH}_{4}>95 \%\right.$, $\mathrm{CO}_{2}<1 \%, \mathrm{~N}_{2}<3 \%, \mathrm{O}_{2}<0.5 \%$ ), and has been up-scaled in the URBIOFIN biorefinery in a $300 \mathrm{~m}^{2}$ HRAP interconnected to a $0.5 \mathrm{~m}^{3}$ absorption column fed with $12 \mathrm{~m}^{3} / \mathrm{d}$ of biogas and $0.1 \mathrm{~m}^{3} / \mathrm{d}$ of liquid fraction of digestate from the AD of OFMSW. The ratio between the biogas flow rate and the liquid recirculation flow rate in the absorption column, and the $\mathrm{pH}$ and alkalinity of the cultivation broth in the HRAP, have been consistently shown as the most relevant operational parameters determining biomethane quality in this innovative biotechnology [52]. Overall, photosynthetic biogas upgrading in algal-bacterial photobioreactors could decrease the operating costs of conventional biogas upgrading $\left(\mathrm{H}_{2} \mathrm{~S}\right.$ adsorption by activated carbon filtration $+\mathrm{CO}_{2}$ removal by water absorption) from $0.2 € / \mathrm{Nm}^{3}$ to $0.03 € / \mathrm{Nm}^{3}$, with a concomitant decrease in the energy demand from $0.3 \mathrm{kWh} / \mathrm{Nm}^{3}$ to $0.08 \mathrm{kWh} / \mathrm{Nm}^{3}$ [53]. 
The presence of VMSs in biogas represents an important handicap for the valorization of biogas as a renewable energy source, since VMSs are oxidized to silicon dioxide $\left(\mathrm{SiO}_{2}\right)$ during biogas combustion. These crystalline deposits of $\mathrm{SiO}_{2}$ accumulate in the equipment, reducing the efficiency and increasing the maintenance costs due to corrosion, erosion and clogging of pipelines and engines [54,55]. Therefore, there is an increasing interest in VMSs removal from biogas. In this context, previous research has demonstrated that physical/chemical off-gas treatment technologies exhibit higher economic and environmental impacts than their biological counterparts [48]. In the last 10 years, biological technologies for VMSs removal have been studied, particularly in a BTF configuration. In a BTF, the VMS-laden biomethane passes through a packed bed of synthetic inert material where microbial communities responsible for VMS biodegradation are immobilized as a biofilm (Fig. 2.10). A continuous recirculation of a trickling liquid solution prevents drying of the packing material, provides nutrients for microbial growth

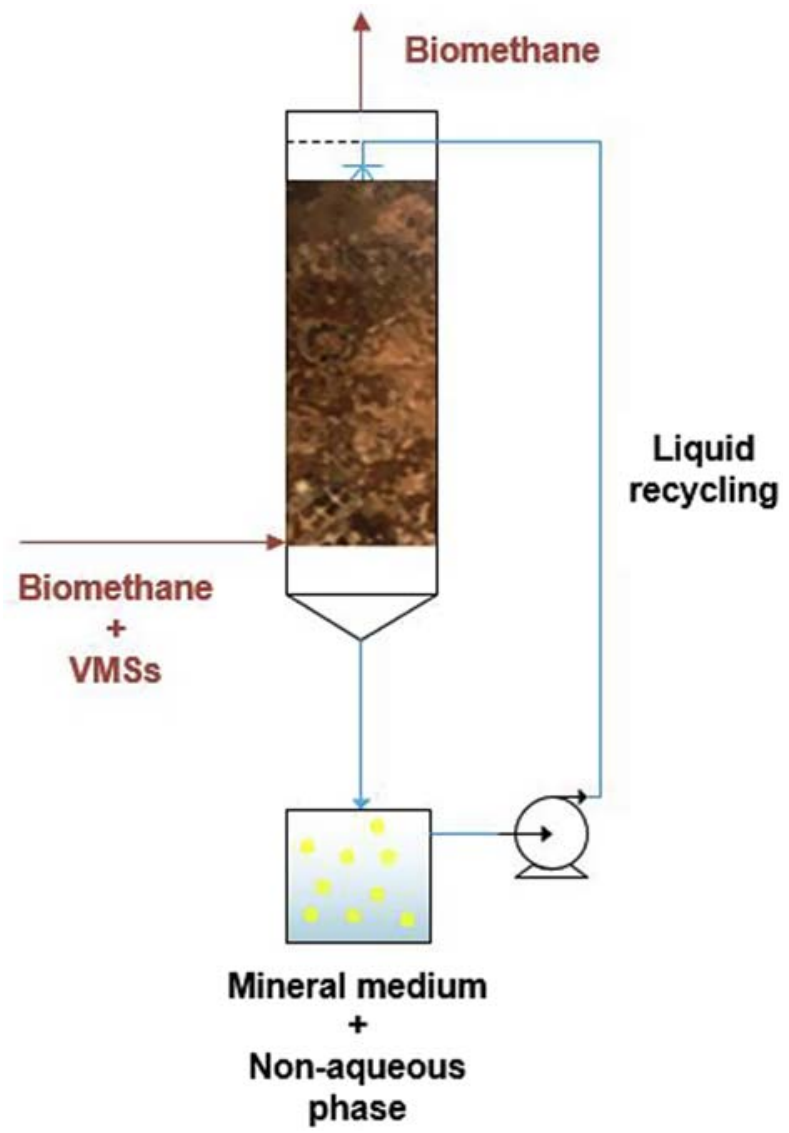

Figure 2.10

Schematic diagram of a two-phase partitioning biotrickling filter for VMSs treatment. 
and wash-out from the biofilm any potential inhibitory metabolite produced during VMS biodegradation [56]. In this context, the operation of a BTF for the treatment of hexamethylcyclotrisiloxane (D3) under aerobic conditions has shown a removal efficiency (RE) of up to 20\% at empty bed residence times (EBRT) of 2.1-3.6 min [54]. Likewise, the operation a BTF for octamethylcyclotetrasiloxane (D4) treatment under anaerobic and aerobic conditions resulted in REs of $43 \%$ at an EBRT of $19.5 \mathrm{~min}$ and $15 \%$ at an EBRT of 4 min, respectively [57]. These investigations suggested that an effective VMSs removal requires (1) high EBRTs, (2) the presence of an organic phase (nonaqueous phase) capable of enhancing the mass transfer of VMSs from biomethane to the microbial community, and (3) a microbial culture previously enriched with the ability to use VMSs as the only carbon and energy source. This technology is currently under optimization in the URBIOFIN biorefinery in a $2 \mathrm{~L}$ lab scale BTF operated with a nonaqueous phase supplemented to the mineral salt medium. The BTF will be inoculated with an enriched VMSs-degrading culture. This technology will be then validated in a $120 \mathrm{~L}$ BTF fed with $7.2 \mathrm{~m}^{3} / \mathrm{d}$ of biomethane from the photosynthetic biogas upgrading unit.

\subsection{PHA production from biogas}

Methane $\left(\mathrm{CH}_{4}\right)$, with a global warming potential 85 times higher than that of $\mathrm{CO}_{2}$ for a 20 years horizon and an atmospheric lifetime of 7-12 years, represents nowadays the second most important greenhouse gas (GHG). Its atmospheric concentration has steadily increased during the 20th century and the first part of the 21 st century, achieving a value of $\approx 1835 \mathrm{ppb}$ in 2015 , an increase by a factor of 2.4 compared with preindustrial levels [58]. Methane concentration in anthropogenic emissions widely vary depending on the source, ranging from $<3 \%$ up to $80 \%$ of $\mathrm{CH}_{4}$ (i.e., land filling, composting, wastewater treatment). While diluted emissions are commonly vented to the atmosphere or flared as they are not suitable for energy recovery, emissions with $\mathrm{CH}_{4}$ concentrations exceeding $20 \%$ are usually combusted for energy production [59]. Nevertheless, these current practices for the management of $\mathrm{CH}_{4}$-loaded emissions entail a negative impact on the environment due to $\mathrm{CH}_{4}$ and $\mathrm{CO}_{2}$ release.

As opposed to traditional end-of-pipe physical-chemical methods for $\mathrm{CH}_{4}$ abatement, biological technologies offer a sustainable and environmentally friendly alternative with lower associated operating costs. These biotechnologies are based on the biocatalytic action of aerobic methane-oxidizing bacteria called methanotrophs, able to degrade $\mathrm{CH}_{4}$ into $\mathrm{CO}_{2}$ and water using $\mathrm{O}_{2}$ as the electron acceptor. Aerobic methanotrophic bacteria belong to the Alphaproteobacteria, Gammaproteobacteria and Verrucomicrobia phyla, and are classified into three groups depending on the carbon assimilation pathway: type I methanotrophs that use the ribulose monophosphate (RuMP) pathway; type II methanotrophs using the serine-pathway; and type X, a subset of type I that uses the 
RuMP pathway for carbon assimilation, but also presents low levels of serine-pathway enzymes $[60,61]$. Moreover, methanotrophs have been reported to produce more than a dozen of different high added-value products using $\mathrm{CH}_{4}$ as a feedstock (bioplastics (PHA), ectoine, biofuels, extracellular polysaccharides (EPS), single cell proteins (SCP), etc.). In this context, the implementation of a $\mathrm{CH}_{4}$ biorefinery combining the abatement of this GHG contained in biogas and the production of multiple valuable byproducts has been recently investigated in order to boost the economic viability of biological $\mathrm{CH}_{4}$ treatment technologies (Table 2.2).

Among these marketable products, PHAs represent one of the most profitable in terms of productivity, production-derived costs and proximity to market [63]. PHAs such PHB or poly-3-hydroxyvalerate (PHV) are biopolymers with comparable mechanical properties to those of polypropylene and polyethylene, besides being biodegradable and biocompatible. These properties make them attractive substitutes to oil-based plastics. These intracellular biopolyesters are produced under nutrient-limiting and $\mathrm{CH}_{4}$-excess conditions by a wide range of microorganisms as carbon and energy storage resources. To date, the high costs of PHA compared to conventional petroleum-based plastics has limited their application, the feedstock cost (usually sugar from corn or sugar cane) accounting for more than $30 \%$ of the total production costs [62]. Therefore, $\mathrm{CH}_{4}$ represents a low cost and environmentally friendly alternative substrate for the synthesis of PHA with a more competitive market price.

Production of PHA seems to be exclusively related to type II methanotrophs, since previous studies have suggested that PHA synthesis is linked to the serine cycle, whereas

Table 2.2: Potential added-value products obtained from methanotrophic strains using $\mathrm{CH}_{4}$ as feedstock $[59,62]$.

\begin{tabular}{|c|c|c|c|c|c|}
\hline Product & Application & $\begin{array}{c}\text { Market price } \\
(€ / \mathrm{kg})\end{array}$ & Genera & $\begin{array}{l}\text { Production yield/ } \\
\text { rate }\end{array}$ & $\begin{array}{l}\text { Demo- } \\
\text { scale }\end{array}$ \\
\hline Ectoine & $\begin{array}{c}\text { Medicine, } \\
\text { cosmetology, } \\
\text { dermatology, } \\
\text { nutrition }\end{array}$ & 900 & $\begin{array}{c}\text { Methylomicrobium } \\
\text { Methylobacter } \\
\text { Methylohalobius }\end{array}$ & $\begin{array}{c}70-230(\mathrm{mg} / \\
\text { g biomass })\end{array}$ & Laboratory \\
\hline PHAs & $\begin{array}{c}\text { Substitutes of } \\
\text { petroleum-based } \\
\text { plastics }\end{array}$ & $4-20$ & $\begin{array}{l}\text { Methylocystis } \\
\text { Methylosinus } \\
\text { Methylocella }\end{array}$ & $\begin{array}{c}200-510(\mathrm{mg} / \\
\text { gbiomass }\end{array}$ & Industrial \\
\hline Methanol & Biofuel & - & $\begin{array}{l}\text { Methylococcus } \\
\text { Methylosinus } \\
\text { Methylocystis }\end{array}$ & $\begin{array}{c}0.13-25 \mu \mathrm{mol} / \\
\left(\mathrm{mg}_{\text {cells }} \mathrm{h}\right)\end{array}$ & Laboratory \\
\hline EPS & $\begin{array}{l}\text { Food, pharmaceutic, } \\
\text { textile, oil industries }\end{array}$ & $4-50$ & $\begin{array}{c}\text { Methylobacter } \\
\text { Methylomonas } \\
\text { Methylomicrobium }\end{array}$ & $\begin{array}{c}300-1800(\mathrm{mg} / \\
\text { gbiomass })\end{array}$ & Laboratory \\
\hline
\end{tabular}


type I methanotrophs produce EPS instead of PHB under unbalanced growth conditions through the RuMP pathway. Moreover, at least three genes (phaCAB) are considered indispensable for PHB production in methanotrophs, encoding the condensation of two acetyl-CoA molecules to acetoacetyl-CoA (phaA), reduction of acetoacetyl-CoA to (R)-3hydroxybutyryl-CoA (phaB), and polymerization of(R)-3-hydroxybutyryl-CoA monomer units into PHB (phaC) [60]. The synthesis of these genes has not been reported in type I methanotrophs. Accumulation of PHA is commonly performed in two stages, the first one aims at obtaining a high cell density culture under nutrient sufficient conditions, which is subsequently subjected to nutrient limitation to promote PHAs accumulation. The type of nutrient limitation applied will affect the maximum PHA content achieved and its molecular weight. Although N-limitation has been the most frequently studied, the influence of limiting other macro- and micronutrients such as $\mathrm{Mn}, \mathrm{Fe}, \mathrm{P}, \mathrm{K}$, or $\mathrm{Mg}$ on PHA yield deserves further investigation [64]. Besides, the addition of VFAs to the cultivation broth might increase PHA yield and tailor the composition of the composite. This option is particularly beneficial when $\mathrm{CH}_{4}$ contained in biogas from AD is used as feedstock, since VFAs would be readily available during AD. In this context, Recent studies demonstrated that the addition of $10 \%$ extra carbon as VFAs resulted in an increase in PHA yield, and valeric acid supplementation supported a higher 3-hydroxyvalerate content in the final biocomposite [65].

Besides the lower production costs of biogas-derived PHA and the demonstrated high accumulation capacity of methanotrophic bacteria, the implementation of this technology is yet constrained by the low aqueous solubility of $\mathrm{CH}_{4}$ and $\mathrm{O}_{2}$ (necessary for $\mathrm{CH}_{4}$ oxidation) which is considered, at this point, as the rate limiting step. Mass transfer of both compounds from the gas to the liquid interphase is limited by their low mass transfer coefficients (dimensionless Henry's law constant, $\mathrm{H}=\mathrm{C}_{\mathrm{G}} / \mathrm{C}_{\mathrm{L}}$, of 29.0 and 31.3, respectively, at $25^{\circ} \mathrm{C}$ and 1 atm) [66]. Thus, reaching high $\mathrm{CH}_{4}$ biodegradation rates and reasonable PHA productivities in the reactor require of prolonged contact times and improved mixing between liquid and gas phases. The increase in residence time is associated to higher reactor volumes that might lead to prohibitive investment costs, while a raise in the system turbulence is often related to excessive operational costs. Therefore, the cost-efficient implementation of this technology requires the development of innovative reactor configurations and smart operational strategies that maximize gas-liquid mass transfer and minimize reactor dimensions. In recent years, two different strategies have attracted the interest of researchers due to their improved performance in the removal of poorly water soluble compounds such as $\mathrm{CH}_{4}$ : (1) the addition of a secondary organic phase (NAP) and (2) the internal recycling of the gas stream [60,67]. NAPs are often nontoxic, nonbiodegradable and biocompatible compounds with high affinity toward $\mathrm{CH}_{4}$ and $\mathrm{O}_{2}$ [68]. These NAPs perform two actions simultaneously that facilitate the biodegradation of the target gas pollutant. On the one hand, NAPs act as pollutant 
reservoir allowing an additional mass transfer route from the NAP to the aqueous phase (in addition to the conventional gas-water mass transfer). On the other hand, the dispersion of these compounds has a positive effect on the hydrodynamics of the gas-liquid system by reducing the size of gas bubbles (which increases interfacial area) and reducing the gas-liquid interfacial tension $[69,70]$. Besides the addition of silicone oil as NAP at $5-10 \% v / v$ has shown an increase in $\mathrm{CH}_{4}$ abatement in bioreactors by a factor of 1.4 , the utilization of a secondary phase during the co-production of PHAs might complicate further downstream processes and deserves additional investigation [71].

Another promising strategy for enhancing gas-liquid mass transfer in bioreactors is the internal recycling of the gas mixture, which permits decoupling the system turbulence and the gas residence time, thus obtaining increased $\mathrm{CH}_{4}$ biodegradation rates and avoiding an increase in reactor volume (or a decrease in overall residence time) [64,67]. This strategy was first employed for methane abatement in packed bioreactors such as BTFs, which are not recommended for co-production of bioproducts given the technical limitations of biomass harvesting [67]. However, in recent years, suspended growth bioreactors equipped with internal gas recycling as well as with other additional fittings for increasing system turbulence such as static mixers, external recycling pipelines, nozzles for gas side streams and additional liquid pumping systems have been used $[64,72,73]$.

Suspended growth bioreactors (stirred tank reactors and bubble column bioreactors) have been traditionally used for fermentation processes due to the possibility of processing in a continuous or quasi-continuous regime at high biomass concentrations and convenient biomass harvesting [74]. However, most studies on PHA production by type II methanotrophs have used stirred tank reactors, which do not represent an economically feasible option at industrial scale due to the high cost dedicated to mechanical agitation of the culture broth. In this regard, bubble column bioreactors are the most promising bioreactors for PHA production given the minimized energy consumption for mixing in the absence of mechanical stirrers and their demonstrated high PHA accumulation capacity $(40 \%-50 \%)[64,75,76]$.

In the URBIOFIN biorefinery, a two-stage system for the anoxic desulfurization and subsequent bioconversion into PHA of $60 \mathrm{~m}^{3} / \mathrm{d}$ of biogas has been designed by the University of Valladolid. The bioconversion of the $\mathrm{CH}_{4}$ contained in the biogas from the $\mathrm{AD}$ of OFMSW will take place in a bubble column bioreactor equipped with internal gas recycling. Biomass growth and the PHA accumulation occurs in a single stage. $\mathrm{CH}_{4}$ removal efficiencies and PHA accumulation capacities over $80 \%$ and $40 \%$ are expected, respectively. $\mathrm{H}_{2} \mathrm{~S}$ must be removed from biogas to prevent clogging of the diffusers in the bubble column reactor. Due to the high operating cost of physical/chemical biogas desulphurization technologies, the biological oxidation of $\mathrm{H}_{2} \mathrm{~S}$ using nitrate as an electron 


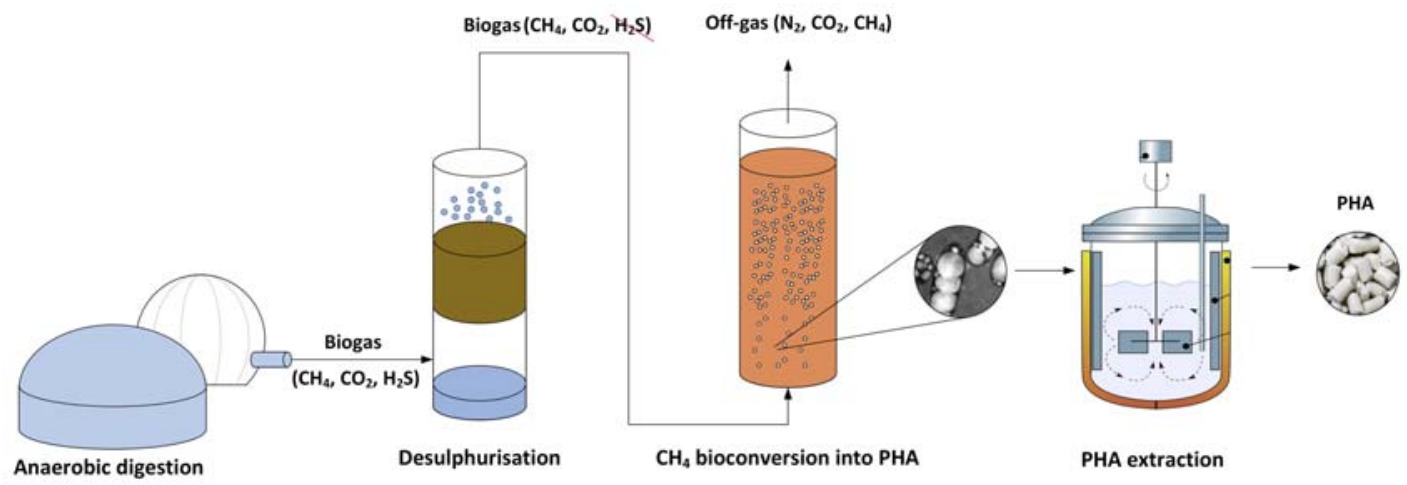

Figure 2.11

Schematic diagram of the biogas desulfurization, $\mathrm{CH}_{4}$ bioconversion into $\mathrm{PHA}$, and $\mathrm{PHA}$ extraction from the microbial cells.

donor in a biotrickling filter was selected as desulfurization technology in the URBIOFIN biorefinery (Fig. 2.11).

\subsection{Biobased fertilizer production}

Cities are major concentrators of materials and nutrients, contained in the urban waste streams, which are mainly extracted from agricultural soils. Nowadays, the return of these nutrients to soil is far from being achieved. At the same time, agricultural practices are leading to progressive soil degradation and mineral fertilizers are massively applied to increase crops productivity. European countries consume 11 Mton of nitrogen $(\mathrm{N})$, 2.5 Mton of phosphate $\left(\mathrm{P}_{2} \mathrm{O}_{5}\right)$ and 2.9 Mton of potash $\left(\mathrm{K}_{2} \mathrm{O}\right)$ each year [77]. Current fertilizers regulatory framework (Regulation 2003/2003/EC) only covers mineral fertilizers [78]. As a part of the Circular Economy Action Plan, a new Fertiliser Products Regulation, FPR has been approved, opening the access to the EU market for biobased fertilizers. It is based on voluntary harmonization and set standards for marketing in Europe under CE mark. Moreover, it will promote the transformation of secondary raw materials into highquality fertilizing products while reducing the dependency of the European Union with respect to the nutrients from third countries, meeting the challenges of sustainable agriculture and promoting a strong Circular Economy in Europe. FPR has been already published in Official Journal of the European Union on June 25, 2019 and will enter into force in 2022.

Organic fertilizer products are currently regulated only at regional and member state level, and its annual consumption (excluding manure) is estimated as $6 \%$ when compared to the inorganic fertilizers $(332,800$ and 549,800 ton of nitrogen and phosphate, respectively) [79]. 
Considering that mineral fertilizer supply is strongly dependent on nonrenewable resources (especially in the case of phosphorus), and that mines are often located in non-EU countries, Europe is making great efforts to promote partial replacement of mineral fertilizers by integrating organic fertilizers derived from recovered biowaste and biomass in the future fertilizers regulation (Proposal COM/2016/0157) [77]. It is expected that the integration of these organic fertilizers into the EU legal framework will also help to reduce both health and environmental risks derived from their application to agricultural soils.

It has been estimated that the total amount of nutrients present in food, animal and human waste on a global scale could represent nearly 2.7 times the nutrients contained on the chemical fertilizers currently used [80]. In particular, OFMSW represents an important source of nutrients. Each person generates annually $483 \mathrm{~kg}$ per capita of MSW, of which up to $50 \%$ in volume is represented by OFMSW [2]. OFMSW separation rates show significant differences between regions and member states. In this regard, with the aim to tackle the environmental impacts associated to landfilling of urban biowaste (i.e., GHGs, leachate formation, etc.), the new directive (UE) 2018/851 on waste commits all member states to separate at the source $55 \%$ of the urban waste for reuse and recycling by the year 2025 [81]. Today, more than half of total MSW generated in European countries is disposed of through landfilling or incineration [2], while the European Compost Network has estimated that $40 \%$ of source-separated municipal biowaste is composted or digested [82]. In total, the annual production of compost is 13 Mton, $79 \%$ coming from green waste and biowaste and $21 \%$ from sewage sludge and mixed waste [83]. It is worth highlighting that compost derived from nonseparately collected OFMSW presents a higher heavy metal concentration and presence of inert materials such as plastics and glass [84].

Urban solid water biorefineries such as URBIOFIN seek for the implementation of circular economy principles for MSW valorization and nutrient recovery through the integration of different biotechnological processes, as can be observed by analyzing the general nutrient flows of the URBIOFIN biorefinery (Fig. 2.12).

In this urban solid waste biorefinery, the carbohydrate fraction of the OFMSW is fermented and converted into bioethanol, which is then catalytically transformed into bioethylene. The residual stream, namely vinasse, is still rich on nutrients ( $\mathrm{N}, \mathrm{P}$ and $\mathrm{K}$ ) and carbon (nondegraded OFMSW and yeast biomass). The vinasse is anaerobically digested together with fresh OFMSW in a 2-phase AD to produce biopolymers and biogas. Most of the N, P, K, and complex organic matter, such as lignin, will remain in the digestate. When digestate is applied as organic fertilizer, this organic carbon remains in the soil after 1 year of its application, thus contributing to hummus build-up. Therefore, the digestate provides a significant enhancement of soil properties [85].

During the $\mathrm{AD}$, organically bound nitrogen is released as ammonium $\mathrm{NH}_{4}{ }^{+}$, becoming directly available for crop uptake. Hence, the efficiency of the digestate as $\mathrm{N}$-fertilizer is 


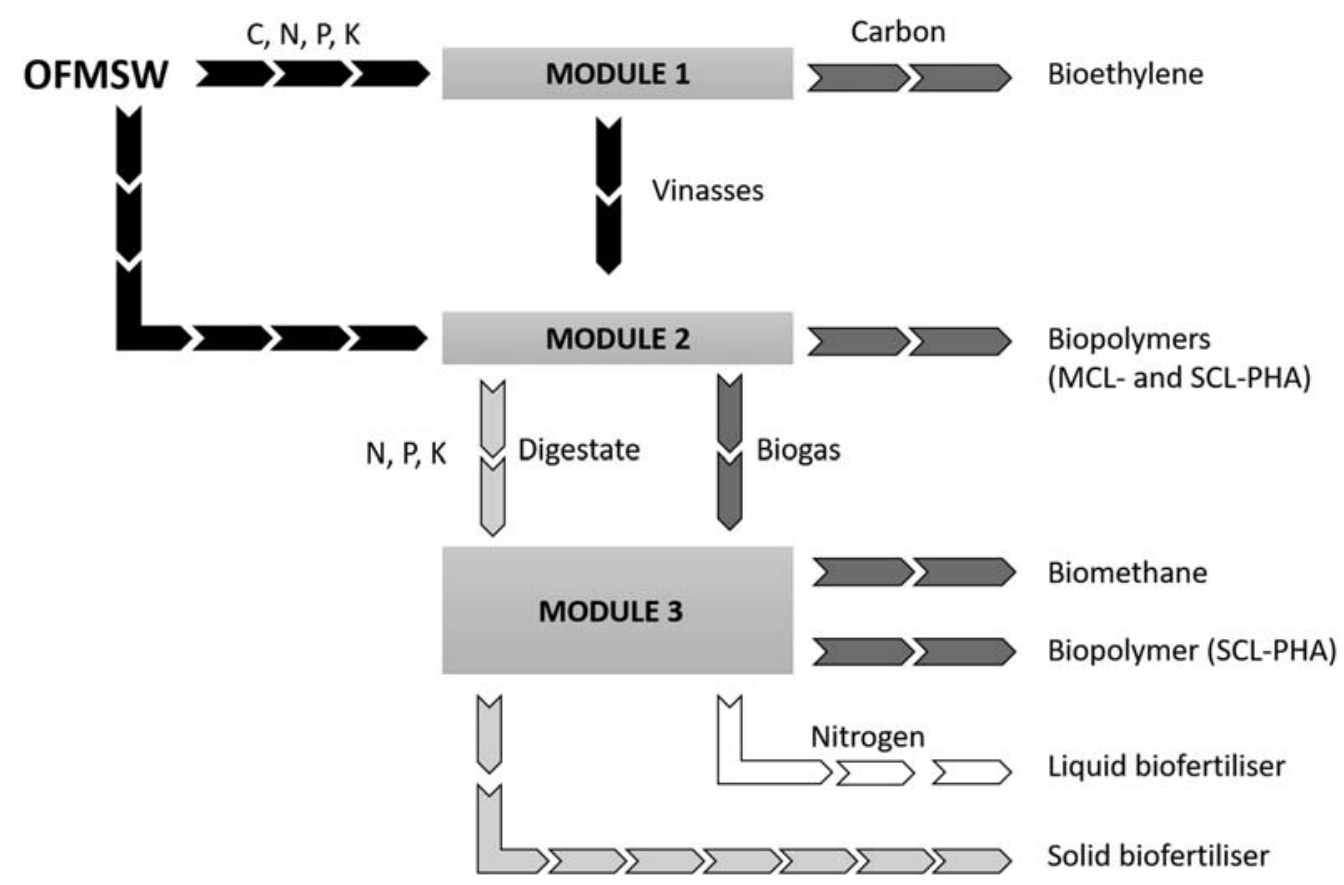

Figure 2.12

Basic nutrient fluxes in URBIOFIN biorefinery. Classified as streams containing only carbon, nitrogen, phosphorous and potassium (black arrows); only carbon (dark grey); mainly nitrogen, phosphorous and potassium (light grey); and mainly nitrogen (white).

highly dependent on $\mathrm{NH}_{4}{ }^{+}-\mathrm{N}$ concentration. OFMSW presents high organic nitrogen content, $7.6 \pm 1.0 \mathrm{~kg} \mathrm{~N} /$ ton on average. The total phosphorus content does not change during $\mathrm{AD}$, but the organically bound $\mathrm{P}$ becomes more available for crops after AD. Likewise, the total $\mathrm{K}, \mathrm{Ca}, \mathrm{Mg}$ and heavy metal content are not altered during $\mathrm{AD}$, but some of them become soluble such as $\mathrm{K}, \mathrm{Ca}$ and $\mathrm{Mg}$. Potential toxic elements, such as $\mathrm{Zn}$ and $\mathrm{Cu}$, may be critical in high concentrations despite being essential micronutrients for healthy plant growth [86].

Regarding biobased fertilizer production, the microalgae unit included in the biorefinery can simultaneously perform biogas upgrading into biomethane and the valorization of the nutrients contained in the liquid effluent streams. The amino acid concentration in the recovered liquid fraction must be determined after hydrolysis and solid-liquid separation of microalgae biomass and a concentration step is necessary to reach an amino acid concentration of $\sim 10 \% \mathrm{w} / \mathrm{w}$, for its final use as a concentrated amino acid-rich liquid biobased fertilizer with biostimulant properties (Fig. 2.13). The final products meet the end-of-waste status as well as technical specifications to fit future fertilizer regulations.

On the other hand, solid organo-mineral biobased fertilizers can be also developed using different waste streams coming from the biorefinery, i.e., solid residue from microalgae 


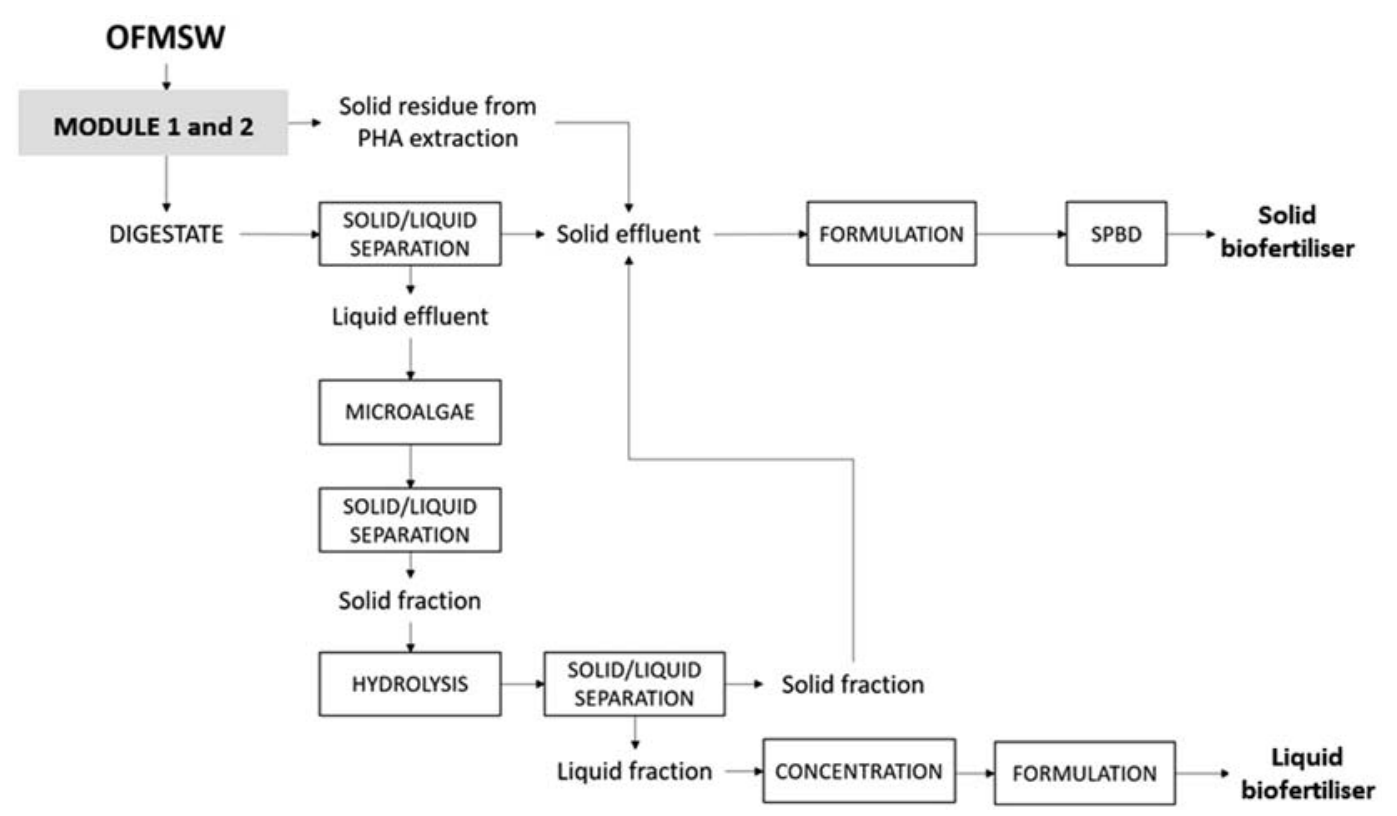

Figure 2.13

Block diagram for the biofertilizer production process in URBIOFIN for both liquid and solid biofertilizers.

hydrolysis, solid residue after PHA extraction, and solid fraction of the digestate (Fig. 2.13). This mixture must be fully characterized (nutrient composition, organic matter content, $\mathrm{pH}$, conductivity and viscosity) in order to formulate the fertilizer product (adjustment of NPK balance, drying and granulation by spouted bed dryer (SPBD)) to accomplish specific requirements to reach the end-of-waste status as well as technical specifications to fit fertilizer legal standards.

\subsection{Integrated URBIOFIN biorefinery: modeling, optimization, and environmental/economic assessments}

Preliminary and subsequent assessments and updates are essential to define the boundaries, parameters, characteristics, and potential in any process engineering work. The modeling of future waste biorefineries is challenging and at the same time promising from a technical, economic, environmental and societal point of view [87]. The urban biorefinery scheme proposed (Fig. 2.1) might offer solutions to the current management of MSW, specifically to the current incineration and disposal of the OFMSW, to produce building blocks and final products that accounts for a higher value than the current end of life solutions [88,89]. Modeling work (Fig. 2.14) can offer alternatives to efficiently study, analyze, optimize, integrate, and up-scale current pilot plants. It can also assess the 


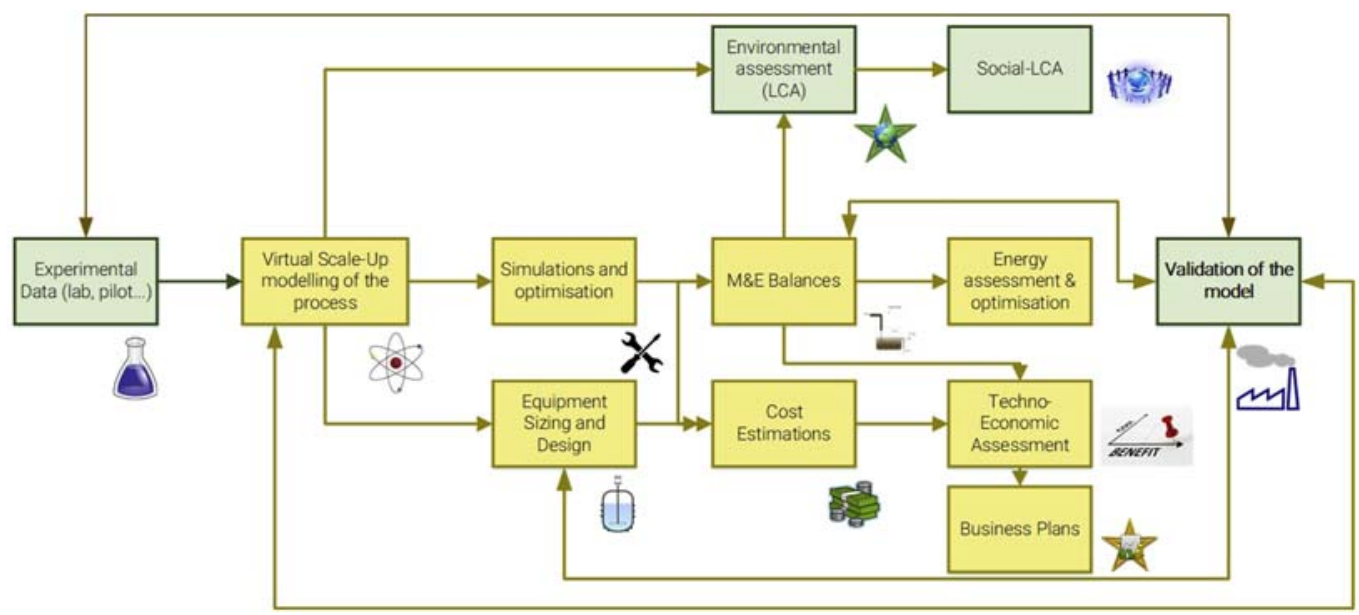

Figure 2.14

Biorefinery modeling and assessment stages. Courtesy of Exergy Ltd. https://exergy-global.com/solutions/ sustainable-processes/.

future potential at larger scale, as well as being able to calculate material and energy (M\&E) balances, study the sensitivity of critical factors or process conditions, and reach optimal results.

Modeling any processing plant is a complex task and some constraints and difficulties (i.e., in terms of calculations) can occur when biomass or nonconventional components, such as MSW, are involved. Decisions such as the thermodynamic model, experimental parameters and physical properties, equipment model selected in the simulator, possibility to integrate pretreatment, upstream and downstream processing, handling solids and accuracy of data (e.g., kinetics, exponential factors, process conditions), among others, will strongly influence the reliability of results from the simulation, and so will influence the behavior of the plant and the balances [90]. Starting from the software, the selection (and management) of the most appropriate software will be critical for the accuracy and reliability of the results to save time and costs. ASPEN Plus [91] software is considered one of the most thorough tools for the modeling and simulation (Fig. 2.1), and subsequently for its further integration and up-scaling of modern biorefineries. Some of the major criteria for the decision are based on (but not limited to) [92]: ASPEN Plus is a robust process simulator and includes tools to work in an environment with solids (critical for the modeling of OFMSW and some of the components). This software has been widely used for the modeling of some bioprocesses, for instance bioethanol production from corn, AD in wastewater or sludge treatment or biodiesel production from algae, is a reliable database, and exhibits the possibility to introduce new compounds and to change/introduce physical properties where appropriate. If an operation is not included in the software, it might be modeled and included using further 
tools such as Aspen Custom Modeler. In addition, ASPEN Plus it is among the most extended and applied software for the simulation of plants worldwide, allows the user to work with solids and includes an economic assessment tool, which can be ran in parallel to process simulations.

Simulations get started by introducing the list of components that are involved in the process. In respect of this, some problems may appear when nonconventional types of feedstock are added. OFMSW is made up of organic compounds that are not available in the ASPEN Plus database, such as glucan, xylan, pectin and lignin. The first three components can be modeled as compounds included in ASPEN Plus database, such as dextrose, xylose, and galacturonic acid, respectively. In the case of lignin, it can be modeled as solid component, however, no physical properties or information is available, which requires the use of the NREL database to complete the gaps [92]. Special mention deserves the option to introduce compounds as nonconventional, which can be the case of the biomass or other solid components that cannot be characterized by a molecular formula. These components are treated as pure components, though they are complex mixtures [93]. The data that is required to use this kind of component is the ultimate and proximate analysis and the enthalpy and density ASPEN models.

Another critical step to consider in a simulation is the selection of the most appropriate thermodynamic method. This essential choice will affect the estimation of accurate physical properties in the simulation. Several factors need to be considered prior to selecting the method: (1) the nature of the properties of interest. In this context, a collection of methods that will best predict the properties or results of interest should be selected. Some of the main properties of interest are enthalpy, heat capacities, viscosity, density, among others; (2) the composition of the mixture since the way to simulate the interactions among the components present in the mixture has an important influence in the results. In this regard, the polarity and molecular structure of the components and the whether the mixture is ideal or nonideal plays a key role in the final outcomes of the simulation; (3) the pressure and temperature range since each thermodynamic method has a certain operating condition where the model itself is valid. For example, activity coefficient methods are mainly described for subcritical systems, below $10 \mathrm{~atm}$, and equation-of-state methods can operate in the critical region, high temperature and pressure; (4) the availability of parameters since the methods used by ASPEN Plus have collected in their database the necessary parameters to solve the equations involved in the models. These parameters are, for example, pure-component and binary parameters that relate the interactions of the components in a mixture [94]. Based on the type of processes involved in the URBIOFIN biorefinery, the previous mentioned considerations and different literature sources, the nonrandom two-liquid activity coefficient model (NRTL) is suggested as the most common method to carry out simulations for these processes, due to its wide application for low-pressure ideal 
and nonideal chemical systems. In addition, this route includes the NRTL liquid activity coefficient model, Henry's law for the dissolved gases and equation of state for the vapor phase, which could be desired to distill ethanol and to handle dissolved gases $[18,92,95]$.

The (techno)economic assessment is revealed as one of the most important tasks to undertake in a project, based on its great influence on the feasibility evaluation. The American National Standards Institute (ANSI) defined three types of estimates: order-ofmagnitude, budget and definitive. Order-of-magnitude estimates have an expected accuracy between $+50 \%$ and $-30 \%$, are generally based on cost-capacity curves and cost-capacity ratios and do not require any preliminary design work. Budget estimates are based on flowsheets, layouts, and preliminary equipment descriptions and specifications and have an accuracy range of $+30 \%$ to $-15 \%$. Design generally must be $5 \%-20 \%$ complete to permit such an estimate to be performed. Finally, definitive estimates require defined engineering data such as site data, specifications, basic drawings, detailed sketches and equipment quotations [96]. Design is generally 20\%-100\% complete and estimate accuracy should be within $+15 \%$ to $-5 \%$. On the other hand, AACE International proposed an expansion of the ANSI estimate classifications to five types with expected accuracy levels based upon the amount of project definition available when the estimate is prepared as shown in Table 2.3 [97]:

Table 2.3: AACE cost estimate classification matrix for process industries.

\begin{tabular}{|c|c|c|c|c|}
\hline $\begin{array}{l}\text { Estimate } \\
\text { class }\end{array}$ & $\begin{array}{l}\text { Degree of project } \\
\text { definition } \\
\text { Expressed as \% of } \\
\text { complete definition }\end{array}$ & $\begin{array}{c}\text { End usage } \\
\text { Typical purpose of } \\
\text { estimate }\end{array}$ & $\begin{array}{c}\text { Methodology } \\
\text { Typical estimating } \\
\text { method }\end{array}$ & $\begin{array}{c}\text { Expected accuracy } \\
\text { range } \\
\text { Typical variation in } \\
\text { low and high } \\
\text { ranges }\end{array}$ \\
\hline Class 5 & $0 \%-20 \%$ & Concept screening & $\begin{array}{l}\text { Capacity factored, } \\
\text { parametric models, } \\
\text { judgment, or } \\
\text { analogy }\end{array}$ & $\begin{array}{c}\mathrm{L}:-20 \% \text { to }-50 \% \\
\mathrm{H}:+30 \% \text { to }+100 \%\end{array}$ \\
\hline Class 4 & $1 \%-15 \%$ & Study or feasibility & $\begin{array}{c}\text { Equipment factored } \\
\text { or parametric } \\
\text { models }\end{array}$ & $\begin{array}{l}\mathrm{L}:-10 \% \text { to }-20 \% \\
\mathrm{H}:+20 \% \text { to }+50 \%\end{array}$ \\
\hline Class 3 & $10 \%-40 \%$ & $\begin{array}{c}\text { Budget } \\
\text { authorization or } \\
\text { control }\end{array}$ & $\begin{array}{l}\text { Semi-detailed unit } \\
\text { costs with assembly } \\
\text { level line items }\end{array}$ & $\begin{array}{l}\mathrm{L}:-10 \% \text { to }-20 \% \\
\mathrm{H}:+10 \% \text { to }+50 \%\end{array}$ \\
\hline Class 2 & $30 \%-70 \%$ & $\begin{array}{c}\text { Control or bid/ } \\
\text { tender }\end{array}$ & $\begin{array}{l}\text { Detailed unit costs } \\
\text { with forced detailed } \\
\text { take-off }\end{array}$ & $\begin{array}{l}\mathrm{L}:-5 \% \text { to }-15 \% \\
\mathrm{H}:+5 \% \text { to }+20 \%\end{array}$ \\
\hline Class 1 & $70 \%-100 \%$ & $\begin{array}{c}\text { Check estimate or } \\
\text { bid/tender }\end{array}$ & $\begin{array}{l}\text { Detailed unit costs } \\
\text { with detailed take- } \\
\text { off }\end{array}$ & $\begin{array}{l}\mathrm{L}:-3 \% \text { to }-10 \% \\
\mathrm{H}:+3 \% \text { to }+15 \%\end{array}$ \\
\hline
\end{tabular}


The degree of accuracy is a function of the project development stage. For this reason, the economic assessment developed at early stages in a project of the nature of URBIOFIN can match with a $-15 \%$ to $-30 \%$ and $+30 \%$ to $+50 \%$ of accuracy. In the first stage, the equipment cost needs to be calculated by consulting both bibliography sources as well as potential suppliers quotations [98-100]. The next step comprises the development of the calculation methodology to estimate key parameters such as capital investment, utilities cost, etc. One method consists of the following conventional procedures for chemical plants based on initial factors due to the possibility to use it in parallel to the technical assessment/modeling of the plant [101]. Together with this methodology, some assumptions need to be taken into account with the aim of obtaining the best preliminary results. Based on the preliminary results, a couple of assertions can be made: (1) the feasibility of the project will strongly affect the sale price of some products such as PHA and liquid fertilizer; (2) the utility that has the largest impact is electricity, influenced by the electricity cost in Spain. The interpretation of these results is important to identify the strengths of the project, so do the availability to integrate the project in an MSW company to reduce equipment cost, the opportunities, production adjustment based on the market product price, plant location, etc., and the improvements, such as more techno-economic accuracy and plan optimization when higher project stages are reached.

The study of the environmental impacts and the comparison to current (incineration, disposal) and alternative (composting, anaerobic digestion) processes are important considerations in order to make final decisions, not only regarding the technical aspects of the project and products, but also from a policy making perspective [102]. Novel biorefinery schemes and bioprocesses are proposed and implemented, including the upgrading of fossil-based plants to biobased or environmentally friendly ones, with the objective to reduce the environmental impact and/or carbon footprint of the final product/s. However, this target is not always reached, and the LCA may show outstanding impacts at some points of the product or processes life cycle, which must be carefully investigated. A complete LCA (Fig. 2.15) is an unavoidable stage to make decisions from different points of view in regard to a novel biorefinery project, and it may influence the future definition of legislative and regulative aspects. A suitable definition of the processes/ products boundaries, (harmonized) functional unit for all processes, scope, inventory, and impact assessment categories, as well as the appropriate interpretation and definition of results will be essential during the LCA [103] as shown in Fig. 2.16. Finally, the comparison to different scenarios will determine the best solution or combination of solutions for our biorefinery unit.

A preliminary LCA in the URBIOFIN biorefinery (which has not considered the integration of the plant as a whole) has reported the following points to be considered in future work: (1) it is necessary to decide whether the plant will be specifically located in a site (specific location) or the data will be used from general sources (i.e., EU data), which 


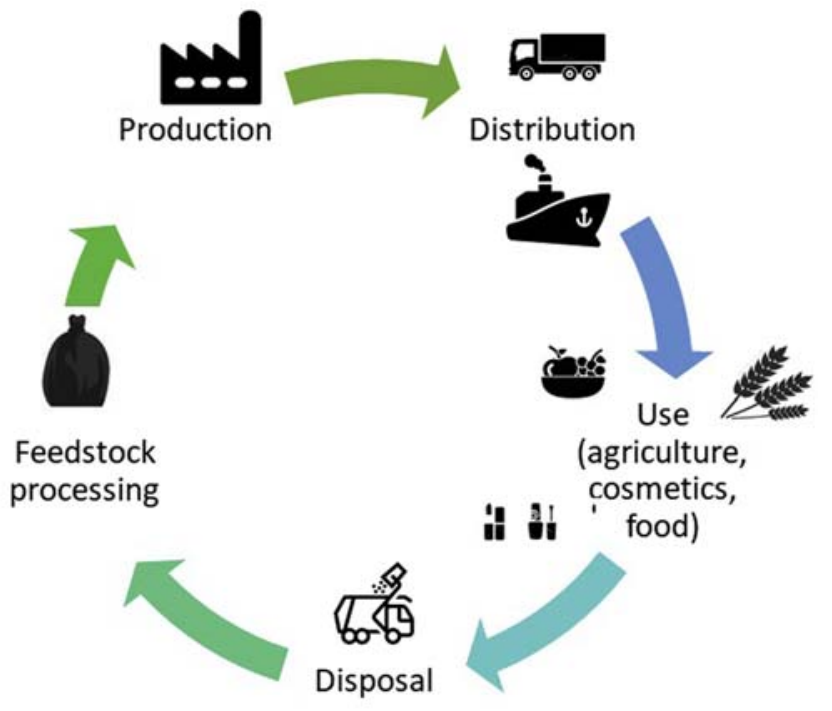

Figure 2.15

URBIOFIN's LCA process stages.

determines the impact of the electricity; (2) in some specific processes, the main impacts are due to other factors, especially the addition of chemicals (flocculants, solvents, sodium-based solutions and mineral salt mediums). These impacts will be further studied in detail associated to the potential plant integration after modeling, also considering a harmonized functional unit to study the process; (3) the potential use of biogas in the

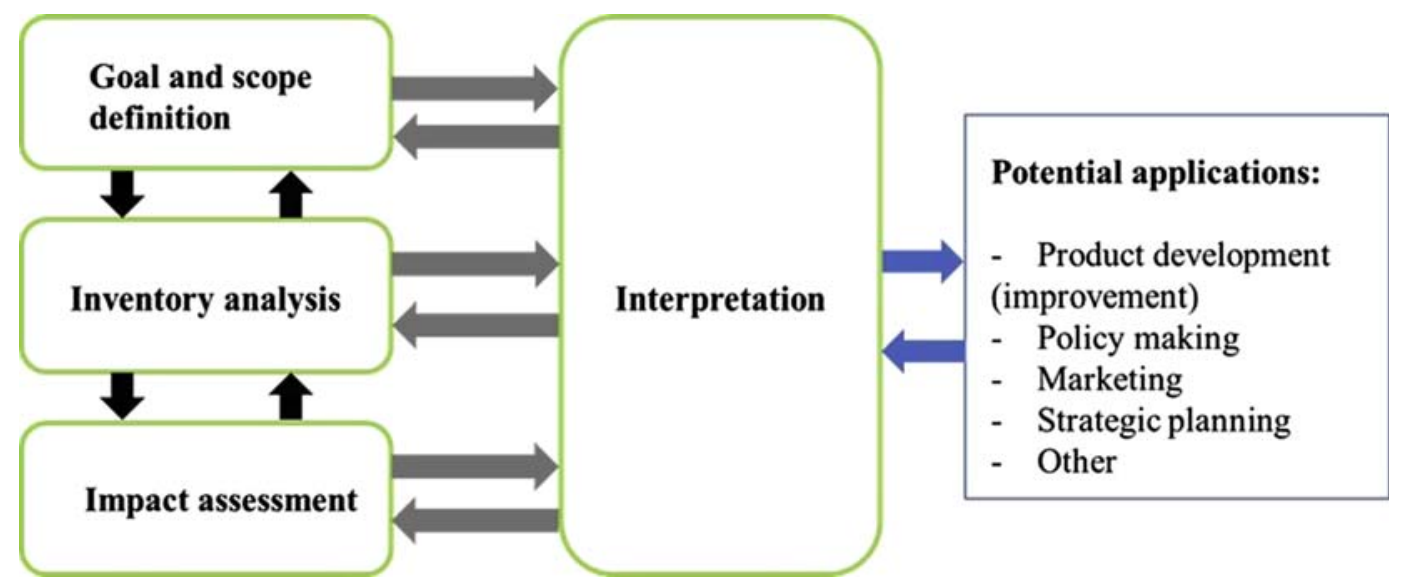

Figure 2.16

LCA stages based on standards ISO 14040, 14041, and 14044. 
integrated plant as a source of energy could contribute significantly to the reduction of the environmental impact associated to the use of fuels and electricity; (4) a common functional unit based either on an integrated plant design or on a common reference point for the mass and energy balances is necessary to compare the different impacts associated to the products and processes.

\subsection{Bioproducts downstream and applications}

The term bioproducts or biobased products refers to products wholly or partly derived from biomass, such as plants, trees or animals (the biomass can have undergone physical, chemical or biological treatment). Some of the reasons of the increasing interest in biobased products lay in their benefits in relation to the depletion of resources and climate change. In this regard, biobased products could provide additional product functionalities, less resource intensive production and efficient use of all-natural resources.

Waste biorefineries such as URBIOFIN can produce a portfolio of different biobased products such as chemical building blocks (bioethanol, VFAs, biogas), biopolymers (PHA and biocomposites) or additives (bioethylene, microalgae hydrolysates for biofertilizers). Thus, URBIOFIN exploits the biowaste fractions of solid household waste as feedstock to transform it into building blocks that can, in turn, be used to produce different valuable marketable biobased products for different markets including agriculture and cosmetics. Beside the technical point of view, URBIOFIN also investigates the minimum requirements for the main bioproducts from a legal scope. Legal requirements are key aspects since it will be crucial to meet them in order to facilitate commercialization. An overview of the main bioproducts and their applications is described in this section.

\subsubsection{PHA}

In the past couple of years, the EU has adopted a number of strategies and regulations that aim to support the transition of Europe's economy from a linear fossil-based economy to a more renewable circular bioeconomy, including measures to improve waste management, increase recycling and usage of more biobased and biodegradable materials. The EU Commission's vision for improving the sustainability of the plastics industry in Europe is a key element of its Circular Economy Strategy. More specifically, EU Plastics Strategy aims to guide the transition of plastics economy using a $3 \mathrm{R}$ (reduce, reuse, recycle) strategy, thus ensuring that all plastic packaging in the EU market will be recyclable by 2030. EU Bioeconomy Strategy is focused on developing EU sustainable and circular bio economy. EU recognizes the importance of bioplastics (like PHA) in this transition, being a sustainable alternative to conventional petrochemicals plastics and thus a crucial component to create a strong and circular European bioeconomy. 
PHAs are a group of biodegradable polymers of biological origin, polyesters produced by a number of bacteria mainly from saturated and unsaturated hydroxyalkanoic acids, and intracellularly deposited as energy storage or reserves. They have attracted considerable industrial interest by replacing the nonbiodegradable plastics derived from petroleum. In contrast to synthetic polymers, PHAs have the fundamental advantage of being based solely on renewable resources, and due to the fact that PHAs are completely digested and metabolized by a wide variety of bacteria and fungi, they are genuinely biodegradable. The variety of their microstructure creates potentially wide variety of biopolymers with different properties that are similar to conventional commodity plastics such as polypropylene, polyethylene and polystyrene. The variation in physical and mechanical properties of the different PHA-types offers a wide range of applications and it has been used to make various products, including films, coated paper, compost bags, disposable food service-ware, and molded products such as bottles and razors. The barrier properties of PHA are also important. Indeed, for products, notably cosmetics one, it is essential that the packaging has a very low permeability in the water and oxygen, in order to preserve or extend the life of the product. It allows a better conservation of the cosmetic properties of the product. Thus, target products for the use of PHA are cosmetic packaging, agricultural films and garbage bags. The PHAs produced in URBIOFIN biorefinery have been designed for molding into packaging by bioplastic companies and are under validation by cosmetic producers who are part of the NATRUE association.

\subsubsection{Biobased fertilizers}

Biofertilizers, also known as "plant probiotics" due to their favorable effects through the interaction between microorganisms, plants, and the environment, represent a segment of agricultural inputs (seeds, agri-chemicals, pesticides, etc.) with a great potential of substitution of the conventional agrichemicals (mineral) solid fertilizers. Their first value is the recovered/renewable origin and reduced environmental footprint of crop production: reduction of fossil fuel consumption, avoiding depletion of nonrenewable mineral fertilizers (P mainly), reduced NOx, and other GHG emissions. Furthermore, they improve soil quality and not only crop productivity. They have particular characteristics regarding the absence of involvement of chemical and/or synthetic products in their manufacture and consequently are suitable for its use in the organic or biological farming.

The stabilized organic matter solid fraction from end-of-waste separate collection can be an excellent raw material for elaboration of substrates, organic fertilizers and biofertilizers, with the requirements of no impurities and pollutants present, low conductivity, no refermentation, and temperature rise episodes. Modern biorefineries have the potential for developing a line of solid biobased fertilizers that will be produced, characterized, tested in laboratory, greenhouse and field and thoroughly 
evaluated. These segment of solid biofertilizers are more competitive with traditional mineral and organo-mineral fertilizers, with greater size but lower value added. In the context of biorefinery, solid and liquid biofertilizers are residuals and sidestreams of biowaste management. The connection between waste management and biotechnology companies should be adjusted and still work beyond the project duration to develop a long-term successful business strategy for the production and commercialization of biofertilizers.

\subsubsection{Bioethylene}

Bioethylene is produced via a biobased process such as dehydration of bioethanol unlike ethylene that in general can be processed with other processes such as steam cracking. Other than the way they are produced, there is not difference to bio ethylene and "normal" ethylene in terms of composition. Ethylene is a hydrocarbon which has formula $\mathrm{C}_{2} \mathrm{H}_{4}$. It's a natural gas without color or odor. Ethylene is the raw material for the most used plastic in the world, polyethylene, made of polymer chains of ethylene units and used as important building block for a broad range of end products. Beside that it is extensively used in agriculture for the ripening of fruits. Fruit ripening is a natural process in which the fruit goes through various chemical changes and gradually becomes sweet, colored, and gets soft and palatable. Often, ripening agents are used to speed up the ripening process. Ethylene is one of the most used agents. Externally applied ethylene is likely to trigger or initiate the natural ripening process of apple, avocado, banana, mango, papaya, pineapple and guava, and therefore, can be marketed before the predicted time.

\subsection{Conclusions and perspectives}

The URBIOFIN biorefinery demonstration plant, originated from the synergistic action of 16 European companies, universities and research centers, represents the most ambitious joint public-private research initiative to create a new model for the management of the organic fraction of MSW aligned with the EU strategy for promoting a circular bioeconomy. By using the biorefinery concept applied to MSW (urban waste biorefinery), the potential of OFMSW can be fully exploited as feedstock, taking into account its heterogeneity and variable composition, to produce at semiindustrial scale different valuable marketable products for local consumption. The project will optimise at a demoscale the transformation of 10 ton/d of OFMSW into bioblocks (bioethanol, volatile fatty acids and biogas), biopolymers (short chain and medium-chain polyhydroxyalkanoates) and additives (bioethylene and biofertilisers) using a battery of innovative physicalchemical and biological processes configured in a three module approach. The technical, environmental and economical sustainability of these technologies will be assessed throughout the project by the whole value chain stakeholders such as waste management 
authorities and companies, technology developers and final products end-users. The main objective of this initiative is to provide an integrated marketable and scalable biorefinery able to obtain higher value bioproducts than biogas and compost than the current MSW treatment.

\section{Acknowledgments}

This publication is part of the project URBIOFIN, which has received funding from the Bio Based Industries Joint Undertaking under the European Union's Horizon 2020 research and innovation programme under grant agreement No 745785. The Regional Goverment of Castilla y León is gratefully acknowledged for the doctoral contract of Victor Perez.

\section{References}

[1] United Nations. World urbanization prospects: the 2018 revision. 2018. Available from:population.un.org/ wup/Publications/Files/WUP2018-KeyFacts.pdf.

[2] Eurostat. Municipal waste statistics. 2018. Available from: ec.europa.eu/eurostat/statistics-explained/ index.php/Municipal_waste_statistics.

[3] Eurostat. Recycling rate of municipal waste. 2018. Available from: ec.europa.eu/eurostat/tgm/table.do? tab $=$ table \&plugin $=1 \&$ language $=$ en $\&$ pcode $=$ sdg_11_60.

[4] European Commission. Implementation of the circular economy action plan. 2018. Available from: ec. europa.eu/environment/circular-economy/index_en.htm.

[5] Statista. Global biofuel production from 2000 to 2017. 2018. Available from: www.statista.com/statistics/ 274163/global-biofuel-production-in-oil-equivalent/.

[6] Weusthuis RA, Aarts JMMJG, Sanders JPM. From biofuel to bioproduct: is bioethanol a suitable fermentation feedstock for synthesis of bulk chemicals? Biofuels Bioproducts and Biorefining 2011;5:486-94.

[7] Rass-Hansen J, Falsig H, Jørgensen B, Christensen CH. Perspective bioethanol: fuel or feedstock? Journal of Chemical Technology and Biotechnology 2007;82:329-33.

[8] Bienfait B, Ertl P. JSME: a free molecule editor in JavaScript. Journal of Cheminformatics 2013;5:24.

[9] Posada JA, Patel AD, Roes A, Blok K, Faaij APC, Patel MK. Potential of bioethanol as a chemical building block for biorefineries: preliminary sustainability assessment of 12 bioethanol-based products. Bioresource Technology 2013;135:490-9.

[10] Balan V, Chiaramonti D, Kumar S. Review of US and EU initiatives toward development, demonstration, and commercialization of lignocellulosic biofuels. Biofuels Bioproducts and Biorefining 2013;7(6):732-59.

[11] Alavi Moghadam MR, Mokhtarani N, Mokhtarani B. Municipal solid waste management in Rasht City, Iran. Waste Management 2009;29(1):485-9.

[12] Balat M, Balat H, Oz C. Progress in bioethanol processing. Progress in Energy and Combustion Science 2008;34:551-73.

[13] Sarkar N, Ghosh SK, Bannerjee S, Aikat K. Bioethanol production from agricultural wastes: an overview. Renewable Energy 2012;37:19-27.

[14] Merchant Research, Consulting Ltd. Ethylene (ET). World market outlook and forecast up to 2027. 2018. Available from: www.e4tech.com/project/from-the-sugar-platform-to-biofuels-and-biochemical/.

[15] Ring KL, deGuzman M. Ethylene. In: Chemical economics handbook. IHS Chemical; 2017. Available from: https://www.ihs.com/products/ethylene-chemical-economics-handbook.html. 
[16] Matar S, Hatch LF. Chemistry of petrochemical processes. Houston, TX: Gulf Professional Publishing; 2001.

[17] Broeren M. Production of bio-ethylene: technology brief. Abu Dhabi: International Renewable Energy Agency (IRENA); 2013.

[18] Mohsenzadeh A, Zamani A, Taherzadeh MJ. Bioethylene production from ethanol: a review and technoeconomical evaluation. ChemBioEng Reviews 2017;4(2):75-91.

[19] Zhang M, Yu Y. Dehydration of ethanol to ethylene. Industrial \& Engineering Chemistry Research 2013;52(28):9505-14.

[20] Bergstra MF. Catalytic ethylene polymerization. Novel reactors for kinetics in gas, slurry and solution processes [Ph.D. thesis]. University of Twente; 2004.

[21] Almeida JRM, Runquist D, Sanchez Nogue V, Liden G, Gorwa-Grauslund MF. Stress-related challenges in pentose fermentation to ethanol by the yeast Saccharomyces cerevisiae. Biotechnology Journal 2011;6(3):286-99.

[22] TNAU Agritech Portal. Fruit ripening report. 2018. Available from: agritech.tnau.ac.in/horticulture/fruit_ ripening.pdf.

[23] Calt E. Products from organic waste using managed ecosystem fermentation. Journal of Sustainable Development 2015;8(3):43-51.

[24] El-Bery H, Tawfik A, Kumari S, Bux F. Effect of thermal pre-treatment on inoculum sludge to enhance bio-hydrogen production from alkali hydrolysed rice straw in a mesophilic anaerobic baffled reactor. Environmental Technology 2013;34(13-14):1965-72.

[25] Xie L, Liu H, Chen Y-G, Zhou Q. pH adjustment strategy for volatile fatty acid production from highstrength wastewater for biological nutrient removal. Water Science and Technology 2014;69(10):2043-50.

[26] Dahiya S, Sarkar O, Swamy YV, Mohan SV. Acidogenic fermentation of food waste for volatile fatty acid production with co-generation of biohydrogen. Bioresource Technology 2015;182:103-13.

[27] Yu L, Bule M, Ma J, Zhao Q, Frear C, Chen S. Enhancing volatile fatty acid (VFA) and bio-methane production from lawn grass with pretreatment. Bioresource Technology 2014;162:243-9.

[28] Dogan E, Demirer GN. Volatile fatty acid production from organic fraction of municipal solid waste through anaerobic acidogenic digestion. Environmental Engineering Science 2009;26(9):1443-50.

[29] Plácido J, Zhang Y. Production of volatile fatty acids from slaughterhouse blood by mixed-culture fermentation. Biomass Conversion and Biorefinery 2018;8(3):621-34.

[30] Yirong C, Zhang W, Heaven S, Banks CJ. Influence of ammonia in the anaerobic digestion of food waste. Journal of Environmental Chemical Engineering 2017;5:5131-42.

[31] Demirel B, Scherer P. The roles of acetotrophic and hydrogenotrophic methanogens during anaerobic conversion of biomass to methane: a review. Reviews in Environmental Science and Bio/Technology 2008;7(2):173-90.

[32] Arslan D, Steinbusch KJJ, Diels L, Hamelers HVM, Strik DPBTB, Buisman CJN, De Wever H. Selective short chain carboxylates production: a review on control mechanisms to direct mixed culture fermentation. Critical Reviews in Environmental Science and Technology 2016;46(6):592-634.

[33] Yin J, Wang Y, Shen D, Wang M, Mo H. Improving production of volatile fatty acids from food waste fermentation by hydrothermal pretreatment. Bioresource Technology 2014;171:323-9.

[34] Pham TN, Um Y, Yoon HH. Pretreatment of macroalgae for volatile fatty acid production. Bioresource Technology 2013;146:754-7.

[35] Anderson AJ, Dawes EA. Occurrence, metabolism, metabolic role and industrial uses of bacterial polyhydroxyalkanoates. Microbiological Reviews 1990;54(4):450-72.

[36] Numata K, Abe H, Iwata T. Biodegradability of poly(hydroxyalkanoate) materials. Materials 2009;2:1104-26.

[37] Sashiwa H, Fukuda R, Okura T, Sato S, Nakayama A. Microbial degradation behavior in seawater of polyester blends containing poly(3-hydroxybutyrate co-3-hydroxyhexanoate) (PHBHHx). Marine Drugs 2018;16:34. 
[38] Chen G-Q. A microbial polyhydroxyalkanoates (PHA) based bio- and materials industry. Chemical Society Reviews 2009;38:2434-46.

[39] Harding KG, Dennis JS, von Blottnitz H, Harrison STL. Environmental analysis of plastic production processes: comparing petroleum-based polypropylene and polyethylene with biologically-based poly$\beta$-hydroxybutyric acid using life cycle analysis. Journal of Biotechnology 2007;130:57-66.

[40] Choi J-I, Lee SY. Process analysis and economic evaluation for poly(3-hydroxybutyrate) production by fermentation. Bioprocess Engineering 1997;17:335-42.

[41] Mozejko-Ciesielska J, Kiewisz R. Bacterial polyhydroxyalkanoates: still fabulous? Microbiological Research 2016;192:271-82.

[42] Wang F, Lee SY. Poly(3-hydroxybutyrate) production with high productivity and high polymer content by a fed-batch culture of Alcaligenes latus under nitrogen limitation. Applied and Environmental Microbiology 1997;63:3703-6.

[43] Kourmentza C, Plácido J, Venetsaneas N, Burniol-Figols A, Varrone C, Gavala HN, Reis MAM. Recent advances and challenges towards sustainable polyhydroxyalkanoate (PHA) production. Bioengineering 2017;4(55):1-43.

[44] Reis MAM, Serafim LS, Lemos PC, Ramos AM, Aguiar FR, Van Loosdrecht MCM. Production of polyhydroxyalkanoates by mixed microbial cultures. Bioprocess and Biosystems Engineering 2003;25:377-85.

[45] Kleerebezem R, van Loosdrecht MCM. Mixed culture biotechnology for bioenergy production. Current Opinion in Biotechnology 2007;18:207-12.

[46] Cruz M, Freitas F, Paiva A, Mano F, Dionísio M, Ramos A, Reis M. Valorization of fatty acidscontaining wastes and byproducts into short- and medium-chain length polyhydroxyalkanoates. New Biotechnology 2016;33(1):206-15.

[47] Wall DM, Dumont M, Murphy JD. Green Gas. Facilitating a future green gas grid through the production of renewable gas. IEA Bioenergy Task 2018;37(2).

[48] Muñoz R, Meier L, Diaz I, Jeison D. A critical review on the state-of-the-art of physical/chemical and biological technologies for an integral biogas upgrading. Reviews in Environmental Science and Bio/ Technology 2015;14(4):727-59.

[49] Shen M, Zhang Y, Hu D, Fan J, Zeng G. A review on removal of siloxanes from biogas: with a special focus on volatile methylsiloxanes. Environmental Science and Technology 2018;25:30847-62.

[50] Bahr M, Diaz I, Dominguez A, Sanchez-Gonzalez A, Muñoz R. Microalgal-biotechnology as a platform for an integral biogas upgrading and nutrient removal from anaerobic effluents. Environmental Science and Technology 2014;48(1):573-81.

[51] Toledo AL, Serejo M, Blanco S, Perez R, Lebrero R, Muñoz R. Photosynthetic biogas upgrading to biomethane: boosting nutrient recovery via biomass productivity control. Algal Research 2016;17:46-52.

[52] Rodero MR, Posadas E, Toledo-Cervantes A, Lebrero R, Muñoz R. Influence of alkalinity and temperature on photosynthetic biogas upgrading efficiency in high rate algal ponds. Algal Research 2018;33:284-90.

[53] Toledo-Cervantes A, Estrada JM, Lebrero R, Muñoz R. A comparative analysis of biogas upgrading technologies: photosynthetic vs physical/chemical processes. Algal Research 2017;25:237-43.

[54] Accettola F, Guebitz GM, Schoeftner R. Siloxane removal from biogas by biofiltration: biodegradation studies. Clean Technologies and Environmental Policy 2008;10:211-8.

[55] Soreanu G, Béland M, Falletta P, Edmonson K, Svoboda L, Al-Jamal M, Seto P. Approaches concerning siloxane removal from biogas - a review. Canadian Biosystems Engineering 2011;53(8):1-18.

[56] Xue N, Wang Q, Wang J, Wang J, Sun X. Odorous composting gas abatement and microbial community diversity in a biotrickling filter. International Biodeterioration \& Biodegradation 2013;82:73-80.

[57] Popat SC, Deshusses MA. Biological removal of siloxanes from landfill and digester gases: opportunities and challenges. Environmental Science and Technology 2008;42:8510-5.

[58] European Environmental Agency. Atmospheric greenhouse gas concentrations (CSI 013/CLIM 052). 2018. 
[59] Lebrero R, Chandran K. Biological conversion of waste methane streams. Critical Reviews in Environmental Science and Technology 2017;47(22):2133-57.

[60] Pieja AJ, Rostkowski KH, Criddle CS. Distribution and selection of poly-3-hydroxybutyrate production capacity in methanotrophic proteobacteria. Microbial Ecology 2011;62:564-73.

[61] López JC, Quijano G, Souza TSO, Estrada JM, Lebrero R, Muñoz R. Biotechnologies for greenhouse gases $\left(\mathrm{CH}_{4}, \mathrm{~N}_{2} \mathrm{O}\right.$, and $\left.\mathrm{CO}_{2}\right)$ abatement: state of the art and challenges. Applied Microbiology and Biotechnology 2013;97:2277-303.

[62] Cantera S, Muñoz R, Lebrero R, López JC, Rodríguez Y, García-Encina PA. Technologies for the bioconversion of methane into more valuable products. Current Opinion in Biotechnology 2018;50:128-35.

[63] Strong PJ, Kalyuzhnaya M, Silverman J, Clarke WP. A methanotroph-based biorefinery: potential scenarios for generating multiple products from a single fermentation. Bioresource Technology 2016;215:314-23.

[64] García-Pérez T, López JC, Passos F, Lebrero R, Revah S, Muñoz R. Simultaneous methane abatement and PHB production by Methylocystis hirsuta in a novel gas-recycling bubble column bioreactor. Chemical Engineering Journal 2018;334:691-7.

[65] López JC, Arnáiz E, Merchán L, Lebrero R, Muñoz R. Biogas-based polyhydroxyalkanoates production by Methylocystis hirsuta: a step further in anaerobic digestion biorefineries. Chemical Engineering Journal 2018;333:529-36.

[66] Sander R. Compilation of Henry's law constants (version 4.0) for water as solvent. Atmospheric Chemistry and Physics 2015;15:399-4981.

[67] Estrada JM, Lebrero R, Quijano G, Pérez R, Figueroa-González I, García-Encina PA, Muñoz R. Methane abatement in gas-recycling biotrickling filter: evaluating innovative operational strategies to overcome mass transfer limitations. Chemical Engineering Journal 2014;253:385-93.

[68] Bruce LJ, Daugulis AJ. Solvent selection strategies for extractive biocatalysis. Biotechnology Progress 1991;7(2):116-24.

[69] Cantera S, Estrada JM, Lebrero R, García-Encina PA, Muñoz R. Comparative performance evaluation of conventional and two-phase hydrophobic stirred tank reactors for methane abatement: mass transfer and biological considerations. Biotechnology and Bioengineering 2016;113:1203-12.

[70] Stone KA, Hilliard MV, He QP, Wang J. A mini review on bioreactor configurations and gas transfer enhancements for biochemical methane conversion. Biochemical Engineering Journal 2017;128:83-92.

[71] Rocha-Rios J, Muñoz R, Revah S. Effect of silicone oil fraction and stirring rate on methane degradation in a stirred tank reactor. Journal of Chemical Technology and Biotechnology 2010;85:314-9.

[72] Petersen LAH, Villadsen J, Jørgensen SB, Gernaey K. Mixing and mass transfer in a pilot scale U-loop bioreactor. Biotechnology and Bioengineering 2017;114:344-54.

[73] Yazdian F, Shojaosadati S, Nosrati M, Pesaran, Mahdi P, Ebrahim V-F. Mixing studies in loop bioreactors for production of biomass from natural gas. Iranian Journal of Chemistry and Chemical Engineering 2012;31:91-101.

[74] Kraakman NJR, Rocha-Ríos J, van Loosdrecht MCM. Review of mass transfer aspects for biological gas treatment. Applied Microbiology and Biotechnology 2011;91:873-86.

[75] Rahnama F, Vasheghani-Farahani E, Yazdian F, Shojaosadati SA. PHB production by Methylocystis hirsuta from natural gas in a bubble column and a vertical loop bioreactor. Biochemical Engineering Journal 2012;65:51-6.

[76] Pieja AJ, Sundstrom ER, Criddle CS. Cyclic, alternating methane and nitrogen limitation increases PHB production in a methanotrophic community. Bioresource Technology 2012;107:385-92.

[77] Fertilizers Europe. Annual overview 2018. 2018. Available from: www.fertilizerseurope.com/uploads/ media/Fertilizers_Europe_Annual_Overview_2018.pdf.

[78] Regulation (EC) No 2003/2003 of the European Parliament and of the Council of 13 October 2003 relating to fertilisers. November 21, 2003. Official Journal of the European Union. 
[79] Proposal COM/2016/0157 final - 2016/084 (COD), for regulation on the making available on the market of CE marked products fertilising and Amending Regulations (EC) No 1069/2009 and (EC) No $1107 / 2009$.

[80] Ellen MacArthur Foundation, Towards the circular economy, vol. 2.

[81] Directive 2018/851/CE of the European Parliament and of the Council of 30 May 2018, amending directive 2008/98/EC on waste. Brussels, Belgium.

[82] ECN 2017/01. European Compost Network Newsletter. Available from: www.compostnetwork.info/ wordpress/wp-content/uploads/170713_ECN-NEWS-01_2017.pdf.

[83] ORBIT/ECN. Compost production and use in the EU. 2008. Available from: www.organicsrecycling.org. uk/dmdocuments/compostproduction_and_usein_EU.pdf.

[84] Cesaro A, Belgiorno V, Guida M. Compost from organic solid waste: quality assessment and European regulations for its sustainable use. Resources, Conservation and Recycling 2015;94:72-9.

[85] Vaneeckhaute C, Lebuf V, Michels E, Belia E, Vanrolleghem PA, Tack FMG, Meers R. Nutrient recovery from digestate: systematic technology review and product classification. Waste and Biomass Valorization 2017;8:21-40.

[86] Hillel D. Soil in the environment: crucible of terrestrial life. New York City: Academia Press; 2008.

[87] Urbiofin Urban Biorefinery: from waste to bioproducts through biorefinery. Available from: https://www. urbiofin.eu/.

[88] MAGRAMA. Management of biowastes of municipal competition. Guide for the implementation of selective collection and treatment of the organic fraction. 2013. Spain.

[89] Tyagi VK, Fernandez-Guelfo L, Zhou Y. Anaerobic co-digestion of organic fraction of municipal solid waste (OFMSW): progress and challenges. Renewable and Sustainable Energy Reviews 2018;93:380-99.

[90] Al-Malah KIM. Aspen Plus: chemical engineering applications. 1st ed. John Wiley \& Sons; 2016.

[91] Aspentech. Aspen Plus. 2018. Available from: www.aspentech.com/en/products/engineering/aspen-plus.

[92] Wooley RJ, Putsche V. Development of an ASPEN PLUS physical property databased for biofuels components. United States: n.p.; 1996.

[93] Aspentech. Aspen physical property system V9 physical properties. 2016.

[94] Carson EC. Don't gamble with physical properties for simulations. Chemical Engineering Progress 1996;92(10):35-46.

[95] Liu F, Chen G, Yan B, Ma W, Cheng Z, Hou L. Exergy analysis of a new lignocellulosic biomass-based polygeneration system. Energy Journal 2017;140:1087-95.

[96] ANSI. Industrial engineering terminology: cost engineering. 1989.

[97] AACE. Skills \& knowledge of cost engineering. 6th ed. 2015. 0086.

[98] Walas SM. Chemical process equipment: selection and design. 1st ed. Butterworth-Heinemann; 1988.

[99] Warren D, Seider JD, Lewin DR. Product and process design principles. 1st ed. John Wiley and Sons; 1998.

[100] National Energy Technology Laboratory; 2018. Available from: https://www.netl.doe.gov/.

[101] Peters MS, Timmerhaus KD. Plant design and economics for chemical engineers. 4th ed. McGraw-Hill Book; 1968.

[102] Shen Y, Chen TB, Gao D, Zheng G, Liu H, Yang Q. Online monitoring of volatile organic compound production and emission during sewage sludge composting. Bioresource Technology 2012;123:463-70.

[103] International Standards Organization. ISO 14040:2006 environmental management - life cycle assessment - principles and framework. 2006. 